\title{
Thermomechanical Behavior of Damaged TPS Including Hypersonic Flow Effects
}

\author{
Wei H. Ng ${ }^{*}$, Jack J. McNamara ${ }^{\dagger}$, Peretz P. Friedmann ${ }^{\ddagger}$, and Anthony M. Waas ${ }^{\S}$ \\ Department of Aerospace Engineering \\ University of Michigan \\ Ann Arbor, Michigan 48109-2140 \\ Email: peretzf@umich.edu
}

\begin{abstract}
The thermomechanical behavior of damaged space shuttle tile thermal protection system (TPS) is considered. The effects of damage on the thermal protection capability and the induced thermal stresses in the TPS are examined by comparing the thermal and structural response of the damaged configurations with the undamaged configurations. The TPS is subjected to the re-entry heating and pressure profile, and the transient temperature distribution and the resultant thermal stresses in the system are computed using finite element analysis. Three different damage sizes are considered. The validity of the simplifying assumptions is systematically examined. Certain assumptions are relaxed and their effects on the system response are determined. Thermal loads based on high speed flow past a cavity are also incorporated to provide a more accurate model. Damage changes the surface properties of the tile, which significantly reduces the radiation heat loss from the surface of the tile. It also alters the flow field and thus the thermal loads sustained by the TPS, resulting in elevated temperatures. The elevated temperatures combined with the stress concentrations induced by the damage increases the thermal stresses. Results indicate that damage is capable of elevating the maximum temperature in the tile to beyond its melting point and cause structural failure.
\end{abstract}

\section{Nomenclature}

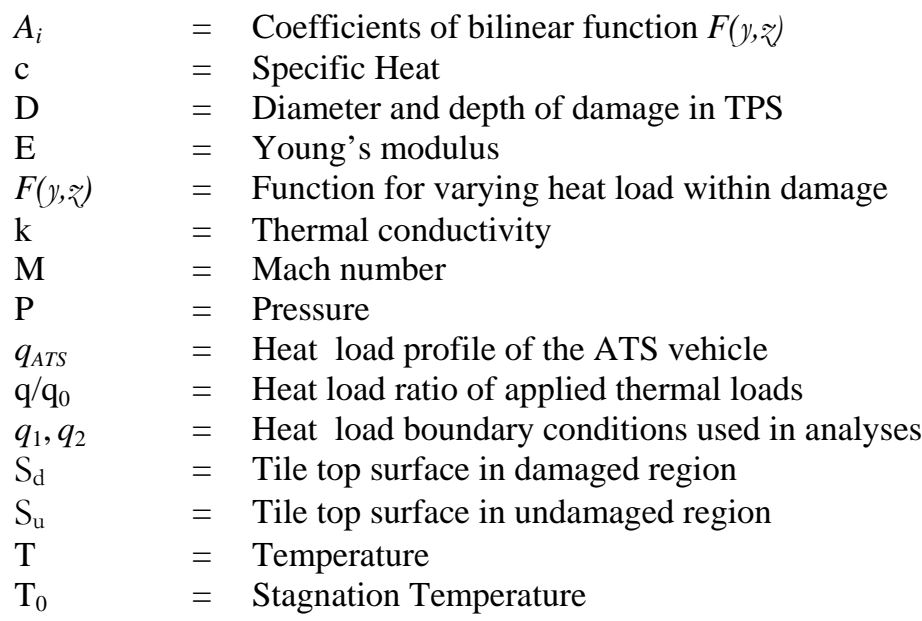

\footnotetext{
* Ph.D. Candidate, Member AIAA

${ }^{\dagger}$ Postdoctoral Scholar, Member AIAA

${ }^{\ddagger}$ François-Xavier Bagnoud Professor, Fellow AIAA, AHS

${ }^{\S}$ Professor, Associate Fellow, AIAA
} 


$\begin{array}{ll}u_{i} & =\text { Displacement in the } i \text {-direction } \\ \mathrm{X} & =\text { Distance along base of cavity for Ref.17 and } 18 \\ x, y, z & =\text { Spatial coordinates for the square configurations } \\ \mathrm{X}_{\mathrm{s}} & =\text { Distance along centerline of damage from upstream-facing lip of damage } \\ \alpha & =\text { Coefficient of thermal expansion (CTE) } \\ v & =\text { Poisson's ratio } \\ \rho & =\text { Density }\end{array}$

\section{Introduction and Problem Statement}

NE of the critical technologies required for hypersonic vehicles is the thermal protection system (TPS) that protects the vehicle and its payload from the high temperatures generated by aerodynamic heating. While stability at high temperatures is a primary factor in the selection of materials for the TPS, other operational requirements, like costs, weight efficiency and thermal compatibility with underlying structure, are also major concerns. For reusable launch vehicles (RLV) the TPS has to withstand not only thermal loads, but also mechanical loads as well as harsh chemical environments, repeatedly without failure. The various TPS that have been developed are described in a paper by Scotti, Clay and Rezin ${ }^{1}$, which presents an overview of the structural and material technologies that are currently in use, as well as potential future candidates for TPS in RLV's.

A variety of TPS have been studied analytically and experimentally. Most studies focus on TPS found on NASA's Space Shuttle, which is a first generation reusable spacecraft. Ko and Jenkins ${ }^{2}$ analyzed the Space Shuttle tile using a one-dimensional temperature profile across the tile's thickness. Sawyer ${ }^{3}$ investigated the strains developed in the shuttle tile due to aerodynamic loads and substructure deformations. Experimental verifications of the shuttle tile performance were carried out by Moser and Schneider, ${ }^{4}$ as well as Cooper et. al. ${ }^{5}$ Operational performance of the TPS obtained from flight tests of the shuttle Columbia was evaluated by Ried et. al., ${ }^{6}$ Dotts, Smith and Tillian, ${ }^{7}$ and Neuenschwander, Mcbride and Armour. ${ }^{8}$ Other TPS, not used on the shuttle, have also been considered. Shideler et. al. ${ }^{9}$ performed several analytical and experimental tests on the multiwall TPS. Milos and Squire ${ }^{10}$ conducted a finite element (FE) analysis of the thermal protection system for the X-34 leading edge. Shideler Webb and Pittman ${ }^{11}$ conducted verification tests on newer TPS concepts, which are less fragile than those currently used on the space shuttle. Thermal and structural FE analyses of an advanced metallic TPS were conducted by Blosser et. al. ${ }^{12}$

In a recent study ${ }^{13}$, the authors examined the thermomechanical behavior of a TPS that consists of the LI-900 high temperature reusable surface insulation tile and a strain isolation pad (SIP) attached to the underlying structure, which is an approximate model of a portion of the space shuttle TPS shown in Figure 1.

Two configurations: a square configuration, shown in Figure 2, which resembles the actual configuration and an axisymmetric configuration, shown in Figure 3, were considered. The damage profile, shown in Figure 3, represents an approximation to the actual "hypervelocity impact" ${ }^{14}$ damage, shown in Figure 4. This approximate damage profile consists of a cylindrical hole, ending with a spherical cap. The depth of the damaged portion is equal to its diameter. The axisymmetric configuration, which is computationally more efficient, is an approximation to the square case. It was found in Ref. 13 that the axisymmetric configuration captures the principal trends displayed in the more accurate square model and therefore is useful for approximate trend type studies. The analyses conducted in Ref. 13 were based on several simplifying assumptions listed below:

1) Emissivity of the LI-900 tile is unaffected by damage and is constant

2) Conductivities of the tile and SIP are assumed to be functions of only temperature

3) LI-900 tile is assumed to be isotropic

4) Mechanical properties of all materials are constants

5) Aerodynamic heating through the damaged region is uniform, spatially

One of the objectives of this paper is to remove the limitations introduced by these simplifying assumptions and examine the TPS under more realistic conditions. A new set of assumptions that remove these limitations, are given below:

1) Emissivity of damaged surface of LI-900 tile is a function of temperature

2) Conductivities of tile and SIP are functions of both temperature and pressure

3) LI-900 tile is transversely isotropic 
4) Certain mechanical properties are functions of temperature

5) Aerodynamic heating through the damaged region is dependent on flow conditions

From Figures 2 and 3, it is evident that the heat load profile on the damaged surface of the tile is dependent on the fluid dynamics of a high speed flow past a cavity. The heat load profile on the damaged surface is unlikely to be uniform, and it will be significantly different from the heat load present on the undamaged surfaces. ${ }^{15,16}$ To improve on the thermomechanical analysis, the flow conditions in the damaged region must be incorporated into the analysis.

Therefore, the specific objectives of this paper are:

a. Examine the effect of removing the simplifying assumptions used previously, and

b. Determine the heat load on the damaged tile by considering the hypersonic flow past a cavity, and incorporate the refined thermal loading into the thermomechanical analysis in order to determine effects of damage on TPS response.

The improved numerical results obtained with the new model, represent a more realistic behavior of the TPS.

\section{Flow Dependent Thermal Loads}

\section{A. Hypersonic Cavity Flow}

Hypersonic flow past a cavity is a challenging problem due to complex flow characteristics, such as hypersonic flow separation. ${ }^{15,17}$ The presence of flow separation is important for the heat transfer problem since the aerodynamic heat load varies spatially as the flow passes over the damaged region separates, and then re-attaches. For cavity geometries similar those shown in Figure 5, this flow problem has been studied both computationally, ${ }^{16,18}$ and experimentally. ${ }^{15,16,17}$ Cavity flows are typically denoted as either "open" or "closed", depending on certain flow characteristics. For open cavity flows, the external flow passes over the cavity and the separated shear layer re-attaches near the top corner of the upstream-facing wall producing circulation inside the cavity as shown in the figure. Conversely, for closed cavity flows, the separated shear layer re-attaches to the cavity floor upon impingement and the separates again as it approaches the upstream-facing wall. ${ }^{16,17,18}$ The combination between the length to depth ratio of the cavity and the speed of the flow determine whether the cavity flow will be open or closed. Typically, supersonic and hypersonic cavity flows are open if the length to depth ratio of the cavity varies from 1 to 10 . Note that the damage considered in this study is for length to depth ratio of 1 , and thus it will produce an open cavity flow.

In this study, two approaches for improving heat load estimate on a damaged tile are considered. In the first approach, the aerothermodynamic flow conditions in the cavity are computed using computational fluid dynamics (CFD) based upon CFL3D ${ }^{19}$ code developed by NASA Langley Research Center. This approach is convenient since the computation can be performed for any damage profile considered in the thermomechanical analysis. Two issues that limit the accuracy of the code are the lack of ability to model real gas effects and the limited information on the local operating conditions near the damaged tile.

In the second approach, an approximate heat load profile is extracted from results provided in recent studies ${ }^{17,18}$ dealing with the Columbia accident investigation and Space Shuttle Return to Flight Program. The advantage of this approach is these results contain both real gas effects and local flow conditions. An additional advantage is the presence of experimental results for validation purposes. The disadvantage in using this approach is the inability to consider in detail the effect of the damage geometry on the heat load profile.

\section{B. Thermal Loads from CFL3D}

CFL3D uses an implicit finite-volume algorithm based on upwind-biased spatial differencing to solve the time-dependent Euler and Reynolds-averaged Navier-Stokes equations. Multi-grid and mesh sequencing are available for convergence acceleration. The algorithm, which is based on a cell-centered scheme, uses upwind-differencing based on either flux-vector splitting or flux-difference splitting, and can sharply capture shock waves. This study utilized the flux-vector splitting scheme.

The grid used to generate aerodynamic heating data for the damaged tile is shown in Figure 6. It consists of $2 \times 433 \times 225$ grid points that extends from 3.5 inches in front of the damaged section to 2.5 inches behind the damaged section, and 4 inches above the tile surface. Note that the damaged portion of the tile considered here consists of a strip having a width of 1 inch, and a depth of 1 inch, and it contained 
$2 \times 151 \times 140$ grid points. This grid geometry implies that only two-dimensional flow past the cavity is considered.

The operating conditions used to generate the aerodynamic heating on the tile are provided in Table 1 . These operating conditions are based on those used in a previous experimental and computational study of hypersonic cavity flows. They were selected since the actual flow conditions on the ATS vehicle are not readily available. These conditions produce laminar flow conditions, and therefore the laminar flow option in CFL3D was implemented. The maximum heat load values for the ATS are assumed to occur during laminar flow conditions, so the use of the laminar flow assumption is appropriate.

Figure 7 shows the heat load ratio profile obtained from the CFL3D simulation. The heat load ratio is defined as the local heating data $(\mathrm{q})$ normalized by reference heating data $\left(\mathrm{q}_{0}\right)$ which are obtained from undamaged smooth surface configuration with the same simulation conditions. The results are plotted as a function of a non-dimensional coordinate $\mathrm{X}_{\mathrm{s}} / \mathrm{D}$. According to the definition of $\mathrm{X}_{\mathrm{s}}$, the downstream-facing wall is located between $0<\mathrm{X}_{\mathrm{s}} / \mathrm{D}<0.5$, the "floor" of the cavity is located between $0.5<\mathrm{X}_{\mathrm{s}} / \mathrm{D}<2.07$, and the upstream-facing wall is located between $2.07<\mathrm{X}_{\mathrm{s}} / \mathrm{D}<2.57$.

Consistent with open cavity flows, ${ }^{15,16,17}$ the heat load ratios within the damage are generally less than 1.0 except for the region near the upstream-facing lip of the damage, where the reattachment of the flow occurs. Elevated heat loads are also evident in a region that covers a small distance downstream of the damage.

\section{Thermal Loads from Published Data}

In Refs. 17 and 18, both computational and experimental aerothermodynamic results were generated for hypersonic flows past rectangular cavities. In Ref. 18, CFD was used to predict the hypersonic aerothermodynamic environment for a Shuttle Orbiter with windside tile damage. Furthermore, the computations were performed at the peak heating trajectory point, using the Langley Aerothermodynamic Upwind Relaxation Algorithm (LAURA) code. Note that this code is intended for hypersonic re-entry physics and chemistry. In Ref. 17, results from wind tunnel experiments were generated for cavities and flow conditions similar to those studied in Ref. 18. The experiments were conducted in the Langley 31-inch Mach 10 tunnel. Note that in both cases the cavity length-to-depth ratio was 7.5. ${ }^{17,18}$

Figure 8 shows heat load ratio profile along the cross section where the maximum heat load ratio is observed within the 3D rectangular cavity for CFD simulation using flight conditions. Due to the presence of corners in the cavity geometry, sharp dips in heat load ratios are observed in the profile.

\section{Applied Thermal Loads}

Figure 9 shows the heat load ratio profiles used in the present study to compute the thermomechanical response of a damaged TPS. The "uniform" profile corresponds to the approximate upper bound heat load from previous study while the other profiles are obtained using the two approaches described above. These profiles are used in the current study as scaling factors to multiply the applied surface heat load in order to determine the heat load in regions affected by damage.

The maximum heat load ratio from the CFL3D results due to flow reattachment at the lip of the upstream-facing wall of the damage, was found to be very large $\left(\mathrm{q} / \mathrm{q}_{0}=21.5\right)$. Such high peak heat load ratios were not observed in experiments. ${ }^{15,17}$ The maximum heat load ratio for an open cavity observed in the experiments described in Ref.17 was approximately 4.5, therefore it was decided that the maximum heat load ratio for the heat load ratio profiles used in this study is limited to 4.5 .

The heat load ratio profile based on published data by Everhart et. al. and Pulsonetti et. al. is denoted here as the EP profile. It should be noted that the heat load ratio results along the vertical walls of the cavity were not presented in Refs. 17 and 18. The variation of the profile between $0<\mathrm{X}_{\mathrm{s}} / \mathrm{D}<0.5$ and $2.07<\mathrm{X}_{\mathrm{s}} / \mathrm{D}$ $<2.57$ was obtained by assuming that the results along the vertical walls are similar to those in the CFL3D profile. Thus the sharp dips in heat load ratios in Figure 8 are not present in the EP profile. The maximum heat load ratio was again limited to 4.5 based on the experiments in Ref. 17.

It is evident that the EP profile is generally more severe than the CFL3D profile. This is probably due to the fact that the cavity length-to-depth ratio for EP profile is much larger than that for the CFL3D profile (7.5 vs 1.0) and it had been noted that heating data in cavities increases with their length-to-depth ratio. The difference may also be due to the use of local flow conditions in the EP profile, compared to freestream conditions used in the CFL3D result. For the EP profile, the flow pass a cavity located on a full vehicle is used. Before the flow reaches the cavity, it has passed through a strong bow shock; resulting in a lower Mach number, a higher temperature, and a higher pressure than freestream conditions. 


\section{Finite Element Analysis}

\section{A. Finite Element Method}

The finite element simulation of the thermomechanical behavior of damaged TPS is based upon the ABAQUS code version $6.4^{20}$ Thermal-mechanical coupling, which represents the conversion of mechanical energy to thermal energy, is neglected, due to the much larger amount of energy supplied to the system through thermal loading. The thermomechanical response of the system is obtained in two steps. First, the heat transfer problem is solved to obtain the time-dependent temperature distribution in the TPS due to the applied thermal loads and boundary conditions. Subsequently, the thermal stresses caused by the temperature distributions are determined. The solutions are facilitated by using the same mesh for both the heat transfer and thermal stress problems.

In the previous study, stress singularities were detected at the edges and corners of the material interfaces. The presence of geometric and material discontinuities in these regions produces a typical "boundary-layer effect", where the stress gradient changes rapidly. Even with significant mesh refinement, difficulty was encountered for producing reliable and converged results. Using the most refined meshes obtainable with the meshing software, converged results from locations sufficiently distant from these stress singularities were computed. Such refined meshes required a very high number of degrees of freedom (dof's), however the accuracy of the solution could not be guaranteed due to the singular nature of the complex boundary stress field.

Tong and Pian ${ }^{21}$ concluded that refining meshes and increasing order of element formulation when using conventional finite elements, is inadequate for producing convergence in elasticity problems with singularities. Therefore the use of the finest possible mesh may not produce an accurate solution. Wang and Yuan ${ }^{22}$ developed a singular composite-edge element which uses stress intensity factors to characterize singular edge stress field. The results in Ref. 22 indicate that stress results using the singular element start to deviate from results based on the conventional element when one is approaching within 5\% (based on specimen length) of the location of the singularity. In the present analysis, the boundary layer effects in the TPS are treated by assuming them to be confined to a region of similar proportions, i.e. 5\%. Using this assumption, a modified portion of the quarter model of the square configuration that is used in this study with the boundary region shaded in grey is depicted in Figure 10. This boundary region is located at the periphery of the TPS with a width of $5 \%$ of its length near the interface. Since the computational results are based on conventional elements, results in the shaded region are considered to be unreliable. This implies that the meshes used in this study produce converged results outside this shaded region.

The square configuration used in the simulation is shown in Figure 11(a). Due to symmetry, the square configuration can be represented by a half model of the TPS. It consists of 112,697 elements with 164,368 nodes. The DC3D10 and C3D10 elements are used for the heat transfer and thermal stress problem, respectively. These are ten-noded quadratic tetrahedron elements, shown in Figure 11(b). For the heat transfer problem, the DC3D10 elements have one degree of freedom per node, the temperature at each node, while for the thermal stress problem; the C3D10 element has three degrees of freedom, i.e. the displacements $u_{x}, u_{y}$ and $u_{z}$ at each node. Additional detail on the analysis can be also found in Ref. 13 .

\section{B. Heat Transfer Analysis}

The limitations imposed by the previous assumptions associated with the material properties of the TPS are examined by removing the simplifying assumptions as indicated in the introduction to this paper. Analysis using previous uniform heat loads is conducted and the results are compared with those obtained from previous study. Subsequently, the new material properties combined with the heat loads based on the flow conditions in the damaged region are incorporated in the simulation to obtain a more realistic thermomechanical behavior of the system.

In the heat transfer analysis in Ref. 13, the transient aerodynamic surface heat load was approximated using the re-entry profile of the Access-to-Space (ATS) reference vehicle, ${ }^{23}$ shown in Figure 12. The sides and the inner surface of the TPS are assumed to be perfectly insulated, which corresponds to a worst-case scenario. While this profile is appropriate for the undamaged portions of the tile, special consideration is required in the damaged region. The tile surface was divided into two regions, as shown in Figure 13. In the undamaged regions of the tile surface, $S_{u}$, the transient heat load was set to $q_{\text {ATS }}(t)$. In the damaged regions of the tile surface, $S_{d}$, two different cases were examined: (1) the heat load was set to zero on $S_{d}$ in order to approximate a lower bound in heating, and (2) the heat load was set to $q_{\text {ATS }}(t)$ in order approximate an upper bound in heating., thus: 


$$
\begin{aligned}
& \text { Lower bound: } \quad q_{1}(t)= \begin{cases}q_{\text {ATS }}(t) & \text { on } \mathrm{S}_{\mathrm{u}} \\
0 & \text { on } \mathrm{S}_{\mathrm{d}}\end{cases} \\
& \text { Upper bound: } \quad q_{2}(t)=q_{\text {ATS }}(t) \quad \text { on } \mathrm{S}_{\mathrm{u}} \text { and } \mathrm{S}_{\mathrm{d}}
\end{aligned}
$$

It should also be noted that these uniform heat loads were chosen because they are similar to the type of heat load that can be applied using radiant heaters. For such conditions, experiments can be conducted in the laboratory to validate the FE analysis.

A second set of results are obtained from a simulation based on applying the flow dependent heat loads. The tile surface was divided into several sections as shown in Figure 14. On the undamaged surface, colored in green, a small region right after the damage is separated to allow elevated heat loads to be applied. Within the damage, the surface was divided into two sections: the downstream-facing section, colored light blue, and the upstream-facing section, colored blue. These two sections are further divided into sub-sections so that reasonable linear or polynomial curve fits can be obtained for the heat load ratio profiles shown in Figure 9.

The curve fits for the heat load ratio profiles are obtained as functions of $y$ only, i.e. the heat load ratio only varies with the depth of the damage. In order to have a three-dimensional variation of the heat load ratio, the curve fits for each subsection are multiplied by a bilinear function of $y$ and $z$ of the form:

$$
F(y, z)=A_{1} y+A_{2} y z+A_{3} z+A_{4}
$$

To determine the coefficients, $A_{1}-A_{4}$, for each subsection, the following assumptions are made:

i. Along the centerline of the damage (red dotted line in Figure 14), the heat load ratio profile is the same as that in Figure 9.

ii. At the outer edge of the damage, the heat load ratio is equal to 1.0 , since the tangent of the edge is parallel to the flow.

iii. Along the yellow dotted line in Figure 14, the heat load ratio at the corners of each subsection is the average of the centerline heat load ratios from the upstream and downstream-facing sections.

Figure 15(a) shows the heat load ratios from the EP profile at the corners of each sub-section within the damage. The exact values from the EP profile are in bold type, while the values based on the assumptions above are in regular type.

Figure 15(b) shows the values that Eq. (3) has to satisfy in order to obtain the required heat load ratios at each corner of the subsections from the curve fits. Using these values, the coefficients, $A_{1}-A_{4}$, for each subsection can be calculated. Essentially, Eq. (3) preserves the EP profile along the centerline of the damage while allowing it to vary linearly with respect to z to the required values at the corners of each subsection.

The primary mechanism of heat loss in the TPS is radiation from the top surface of the tile. Convection heat loss is disregarded. On the undamaged surface, all radiated heat is lost to open space. However, in the damaged region, some of the heat radiated from the damaged surface is intercepted by other surfaces, as shown schematically in Figure 16, resulting in lower net heat loss to space. This cavity radiation in the damaged region is accounted for in the analysis by using the keyword commands *CAVITY DEFINITION and $*$ RADIATION VIEWFACTOR in ABAQUS, which determines the heat exchange between element surfaces within the damaged region.

The TPS is assumed to be exposed to a pressure profile shown in Figure 18. There is relatively small increase in pressure in the initial 2400 seconds, followed by a rapid rise to atmospheric pressure at about 3000 seconds. This pressure profile is also based on the reentry pressure profile for the ATS reference vehicle.

The unsteady heat transfer problem is solved in the time domain by using a carefully selected time-step so as to ensure convergence of the transient solution. This correct time-step is determined by repeatedly solving the heat transfer problem with decreasing time-steps. When the difference in the temperature results between two consecutive time-steps is less than $1.0 \%$, the solution is considered to be converged. 
New nodal temperatures are computed at each time-step based on the time-dependent thermal loading conditions as well as the temperature distribution obtained from the previous time step. The nodal temperatures at each time step are stored for subsequent use by the thermal stress analysis.

\section{Thermal Stress Analysis}

For the first set of heat transfer results using the uniform heat loads, the thermal stress analysis is conducted for two types of boundary conditions, (a) the unrestrained, BC1, and (b) the restrained, BC2 boundary conditions, as done in the previous study. The schematic description of these boundary conditions is provided in Figure 17. The boundary conditions are applied only to the underlying structure since the tile and SIP are attached to the underlying structure in such a manner that they are not load bearing elements. For the second set of heat transfer results involving flow dependent heat loads, only the restrained boundary condition, BC2 was applied, since it is closer to the possible boundary conditions that exist in practice. For both sets of results, symmetric boundary conditions are applied to nodes lying on the plane of symmetry. The displacements and stresses at each time-step are computed using the time-dependent nodal temperatures from the heat transfer solution.

\section{Results and Discussion}

Consider the three-layer LI-900 shuttle tile TPS, where the thickness of the SIP and the underlying structure are 0.173 " and 0.063 " respectively. The thickness of the tile, 2.93 ”, is chosen such that the maximum temperature attained by the underlying structure is limited to $150{ }^{\circ} \mathrm{C}$. The material properties, density $(\rho)$, specific heat $(c)$, thermal conductivity $(k)$, Young's modulus $(E)$, Poisson's ratio $(v)$ and coefficient of thermal expansion $(\alpha)$ used in the analyses for the underlying structure, assumed to be made of aluminum are given in Table 2. The conductivity of the SIP as a function of pressure and temperature are given in Table 3 and its other material properties are shown in Table 4. The conductivity of the LI-900 tile as a function of pressure and temperature can be found in Table 5. The tile is transversely isotropic and its in-plane ( $x$ z-plane) properties are different from the out-of-plane ( $y$-direction) properties. The first value listed is the in-plane conductivity while the value in parentheses is the out-of-plane conductivity. Other material properties of the tile are given in Table 6.

\section{A. Validity of assumptions on material properties used in previous study}

A summary detailing the differences in material properties between previous and improved assumptions is given in Table 7. While incorporating the assumptions of temperature dependency in emissivity, and pressure and temperature dependency in conductivity, some problems with ABAQUS were encountered. To include the temperature dependency in emissivity using ABAQUS requires that the heat transfer analysis be conducted in two stages. An analysis where conductivities of the materials are function of only temperature was conducted as the first stage. The temperature results in the damaged region are stored. In a subsequent analysis, representing the second stage, conductivities of the materials are functions of both temperature and pressure, the temperature results from the first stage are used to govern the selection of emissivity values for the calculations in the second stage. This ensures the correct emissivity data is used. This approximate method yields satisfactory results since the surface temperatures were found to be only marginally affected by the inclusion of pressure dependency in conductivity.

The maximum temperatures that occur in the tile, SIP and underlying structure, including the times when they occur are given in Tables 9 and 10, respectively. Results are given for the earlier, simplified square configuration models from the previous study, as well as for the new refined models for both the baseline and damaged configurations. Two values are provided for each damaged configuration: one for the $q_{1}$ thermal loading case, left column, and the other for the $q_{2}$ thermal loading case, right column. The percentage changes in the maximum temperatures for the damaged configurations compared to the undamaged, baseline configurations are also provided.

The lower bound temperatures for all TPS components are relatively insensitive to the changes in the assumptions. For the upper bound temperatures, the reduction in emissivity in the damage raises the temperatures significantly. The effects of damage size on these temperatures are also more severe with the new refined assumptions. Maximum temperatures in the SIP and underlying structure also occur at earlier times because of the higher conductivities of the tile and SIP due to high pressures in the later part of the analysis. 
Tables 11 to 13 provide the maximum von Mises stress in the tile, SIP and underlying structure for the square configurations, and the times at which they occur for both thermal loading cases from Ref. 13, while Tables 14 to 16 present the same information using the new assumptions. In the tables, two maximum stresses, one for the unrestrained boundary condition, BC1, and one for the restrained boundary condition, $\mathrm{BC} 2$, are provided. The percentage changes in these stresses in the damaged configurations, with respect to the baseline configuration, are also indicated.

For the lower bound loading case, the maximum stresses in the tile are quite similar. The maximum difference between the two sets of results at approximate $-5.5 \%$. For the upper bound loading case, the differences are larger. The higher temperatures in the tile as a result of the new assumptions did not produce higher maximum stresses. The maximum stresses are actually lower due to the lower CTE used. The differences in the results are between $13 \%$ and $44 \%$.

In the SIP, maximum stresses using the new assumptions are higher in the BC1 cases while that for the BC2 cases are generally lower. The differences in results vary between $-51 \%$ and $+50 \%$. These differences are due to a combination of higher temperatures and the larger CTE mismatch between the tile and the underlying structure.

With the new assumptions, the maximum stresses in the underlying structure for the BC1 cases are generally lower while those for the BC2 cases are all higher. Differences in results are between $-36 \%$ and $+26 \%$. The higher temperatures and the changing CTE and stiffness of the underlying structure with respect to temperature are the primary cause of the differences.

It is evident that the simplifying assumptions used in the previous analysis have produced results that have substantial errors. It is not possible to choose simplifying assumptions that guarantee conservative results. Therefore, it is important to use the more refined models that incorporate realistic assumptions.

\section{B. Thermomechanical behavior of TPS subjected to flow dependent heat loads}

The maximum temperatures and von Mises stresses that occur in the tile, SIP and underlying structure, including the times when they occur are shown in Tables 17 and 18 respectively. Note that the von Mises stress results are only for the BC2 boundary condition. Two values are provided for each damaged configuration: one for the CFL3D thermal loading case provided in bold type in left column and the other for the EP thermal loading case, italicized in right column. The percentage changes in the maximum temperatures and von Mises stresses for the damaged configurations compared to the undamaged, baseline configuration are also provided in the tables.

1. Comparison between Uniform, CFL3D and EP results

The flow dependent heat loads (CFL3D and EP) are generally of lower magnitude than the uniform heat load except for two regions; a very small region at the upper lip of the downstream-facing section and a larger region on the upper lip of the upstream-facing section. In these regions, the peak heat load for both flow dependent heat profiles are larger than the uniform heat load by a factor of 4.5. Thus, it is not unreasonable to assume that such a large spike in heat load would generate much higher maximum temperatures in the tile. However, the maximum temperatures in the tile due to flow dependent heat loads are similar in magnitudes as those obtained from uniform heat loads with the CFL3D heat load producing the lowest maximum temperatures and the EP heat load producing the highest. There are several reasons for this. First, at such high temperatures, heat loss by radiation is so efficient $\left(\propto \mathrm{T}^{4}\right)$ that even with a large increase in heat load, the increase in temperatures are relatively modest. Second, the uniform heat profile, where all surfaces within the damage are subjected to the same heat load as the surface, is actually quite severe. Third, for the flow dependent heat profiles, other than the two small areas which experience higher heat loads, much of the surfaces within the damage region are subjected to substantially lower heat loads than for the uniform profile. Since cavity radiation allows heat exchange between surfaces within the damage, the heat load based on the CFL3D profile is low enough to produce lower maximum temperatures in the tile. The EP profile has generally higher heat load ratios than the CFL3D profile, and thus produces higher temperatures. It is also interesting to note that similar elevated heat load on the undamaged surface downstream of the damage, where there is neither cavity radiation nor reduction in emissivity, produces maximum temperatures that are between 15 - $22 \%$ less than those within the damage.

The maximum temperatures within the tile for the flow dependent heat loads occur near the upper lip of the upstream-facing section of damage while those for the uniform heat loads occur near the base of the damage. Since the uniform heat load brings higher temperatures deeper into the damage, maximum temperatures for the SIP and underlying structure are also much higher than those obtained using flow 
dependent heat loads. For damaged configurations with the $D=1.5$ ”, the temperatures are higher by up to $78.4 \%$ and $26.7 \%$ than those based on the CFL3D and EP results respectively.

The maximum von Mises stresses in the tile for the flow dependent heat loads are higher than those for uniform heat load in all cases. Even though maximum temperatures may be lower, the heat spike present in the flow dependent heat loads results in larger thermal gradients in the tile, thus producing higher stresses. The EP results are higher than the CFL3D based results due to the higher temperatures. In the SIP and underlying structure, the maximum stresses seem to be directly related to the increases in temperatures within each component. Thus, the results based on the uniform heat load are the highest, followed by the EP and CFL3D results.

2. Effects of damage on TPS

For the tile, the smallest damage considered with the CFL3D heat load increases the maximum temperature by $73.6 \%$ to $1703{ }^{\circ} \mathrm{C}$ which is slightly lower than the melting point of the tile $\left(1704{ }^{\circ} \mathrm{C}\right)$. In all other cases, the melting temperature of the tile were exceeded. At the largest damage size considered, the EP heat load increase the maximum temperature to $2313{ }^{\circ} \mathrm{C}$, a massive increase of $135.8 \%$. However, it should be mentioned that the EP profile was for a cavity that has a much larger length-to-depth ratio than the CFL3D results. Temperatures in the SIP and underlying structure are also increased significantly, by up to $101 \%$. However, the results indicate that only for the $D=1.5$ ” cases that the imposed limit temperature of the underlying structure $\left(150^{\circ} \mathrm{C}\right)$ is exceeded while the vehicle is still in flight $(<3000 \mathrm{~s})$

Note that the thermal stress results are obtained while disregarding the melting temperature of the tile. The presence of damage increases the maximum von Mises stresses in the tile substantially. The smallest size damage considered increases the maximum stresses by more than $100 \%$. The large increase in stresses is a result of the stress concentration due to damage as well as the severe thermal gradients generated by the flow dependent heat loads. For the cases based on CFL3D, maximum stresses decrease with damage size, even when maximum temperatures increase. This suggests that the severity reduction of the stress concentration outweighs that of the increase in maximum temperatures due to increase in damage size. For the EP cases, the stresses are found to increase with increasing damage size.

The maximum stresses for the SIP increases with increasing damage size while those for the underlying structure decrease initially then increase with respect to damage size. Only in one instance was the maximum stress found to be above the failure strength of the material and this occur for the EP case with $D$ $=1.5$ " in the underlying structure. However, at such stresses, it is certainly possible that the buckling load of the underlying structure had already been exceeded, even for other cases. On the other hand, it should be noted that no heat loss through the inner surface of the structure was assumed, a conservative assumption

\section{Concluding Remarks}

The simplifying assumptions used in the previous paper limit the accuracy of the analyses. The effects of these assumptions were examined by comparing the present results with the earlier results. For the cases considered, which include three very dissimilar materials operating under a wide range of temperature and pressure conditions, these simplifying assumptions were found to affect the accuracy of the results in a complicated manner. The complexity of the results presented is such that one cannot conclude in a definitive manner whether the simplifying assumptions were conservative. Thus, it is recommended to avoid using such simplifying assumptions. Reliable results for reusable TPS should be based on realistic material properties and loading conditions; as indicated by the refined results obtained in this paper.

The thermomechanical analyses of the system obtained with the refined assumptions yields several valuable results discussed in detail in the results section. These results indicate that the presence of damage can elevate the maximum temperature in the tile beyond its melting point and cause structural damage in the underlying structure.

The TPS is a critical component of space transport systems and failure can have catastrophic consequences. Thus, understanding the effects of damage on the TPS is of fundamental importance. The results presented provide valuable insight to the damage tolerance of TPS and can eventually be used in the development of more damage tolerant TPS.

\section{Acknowledgments}

This work was supported by the Space Vehicle Technology Institute under grant NCC3-989 jointly funded by NASA and DOD within the NASA Constellation University Institutes Project, with Claudia Meyer as the project manager. 


\section{References}

1 Scotti, S.J., Clay, C. and Rezin, M., "Structures and Materials Technologies for Extreme Environments Applied to Reusable Launch Vehicles". AIAA/ICAS International Symposium and Exposition, AIAA Paper 2003-2697, Dayton, OH, Jul. 2003.

2 Ko, W.L. and Jenkins, J.M., "Thermal Stress Analysis of Space Shuttle Orbiter Wing Skin Panel and Thermal Protection System”, NASA Technical Memorandum 88276.

3 Sawyer, J.W., "Effect of Strain Isolator Pad on Inplane Strain in Shuttle Orbiter Thermal Protection System Tiles", NASA Technical Paper 2141.

4 Moser, T.L. and Schineider, W.C., "Strength Integrity of the Space Shuttle Orbiter Tiles", AIAA-812469, $1^{\text {st }}$ Flight Testing Conference, Las Vegas, NV, NOV. 1981.

5 Cooper, P.A., Miserentino, R., Sawyer, J.W. and Leatherwood, J.D., "Effect of Simulated Mission Loads on Orbiter Thermal Protection System Undensified Tiles", Journal of Spacecraft and Rockets, Vol. 21, No. 5. Sep-Oct 1984

6 Ried, T.C., Goodrich, W.D., Li, C.P., Scott, C.D., Derry, S.M. and Maraia, R.J., "Space Shuttle Orbiter Entry Heating and TPS Response: STS-1 Predictions and Flight Data”, NASA Conference Publication 2216, Pg. 327-347, 1982

7 Dotts, R.L., Smith, J.A. and Tillian, D.J., "Space Shuttle Orbiter Reusable Surface Insulation Flight Results”, NASA Conference Publication 2283, Part 2, Pg. 949-966, 1983.

8 Neuenschwander, W.E., McBride, D.U. and Armour, G.A., "Shuttle TPS Thermal Performance and Analysis Methodology”, NASA Conference Publication 2283, Part 2, Pg. 1025-1064, 1983.

9 Shideler, J.L., Kelly, H.N., Avery, D.E., Blosser, M.L. and Adelman, H.M., "Multiwall TPS - An Emerging Concept”, Journal of Spacecraft and Rockets, Vol. 19, No. 4, Jul-Aug 1982.

10 Frank S. Milos and Thomas H. Squire, "Thermostructural Analysis of X-34 Wing Leading-Edge Tile Thermal Protection System”, Journal of Spacecraft and Rockets, Vol. 36, No. 2, Mar-Apr 1999.

11 Shideler, J.L., Webb, G.L. and Pittman, C.M., "Verification Tests of Durable Thermal Protection System Concepts", Journal of Spacecraft and Rockets, Vol. 22, No. 6, Nov-Dec 1985.

12 Blosser, M.L., Chen, R.R., Schmidt, I.H., Dorsey, J.T., Poteet, C.C. and Bird, R.K., "Advanced Metallic Thermal Protection System Development”, AIAA $40^{\text {th }}$ Aerospace Sciences Meeting \& Exhibit, AIAA Paper 2002-0504, Reno, NV, Jan. 2002

13 Ng, W.H., Friedmann, P.P, Waas, A.M., "Thermomechanical Analysis of a Damaged Thermal Protection System”, AIAA Paper No. 2005-2301, 46 th AIAA/ASME/ASCE/AHS/ASC Structures, Structural Dynamics, and Materials Conference, Austin TX, Apr 2005

14 Christiansen, E.L. and Friesen, L., "Penetration Equations for Thermal Protection Material", International Journal Impact Engineering, Vol. 20, Pg. 153-164, 1997

15 Nestler, D.E., Saydah, A.R. and Auxer, W.L., "Heat Transfer to Steps and Cavities in Hypersonic Turbulent Flow", AIAA Paper No. 68-673, AIAA Fluid and Plasma Dynamics Conference, Los Angeles CA, Jun 1968

16 Soltani, S. and Hillier R., “An Experimental and Computational Study of Hypersonic Cavity Flows”, AIAA paper No. 94-0766, 32 ${ }^{\text {nd }}$ Aerospace Sciences Meeting and Exhibit, Reno NV, Jan 1994

17 Everhart, J.L., Alter, S.J., Merski, N. R., Wood, W. A., and Prabhu, R.K., "Pressure Gradient Effects on Hypersonic Cavity Flow Heating,” AIAA Paper No. 2006-185, $44^{\text {th }}$ Aerospace Sciences Meeting \& Exhibit, January 2006.

18 Pulsonetti, M. V., and Wood, W., "Computational Aerothermodynamic Assessment of Space Shuttle Orbiter Tile Damage - Open Cavities," AIAA Paper No. 2005-4679, $38^{\text {th }}$ AIAA Thermophysics Conference, June 2005.

19 Krist, S.L., Biedron, R.T. and Runsey, C.L., “CFL3D User’s Manual” (Version 5.0), NASA, RM 1998-208444, 1997

20 “ABAQUS/Standard User’s Manual Version 6.4,” Hibbitt, Karlsson \& Sorensen, Inc., Pawtucket, RI.

21 Tong, P., and Pian, T.H.H., "On Convergence of the Finite Element Methods for Problems with Singularity,” International Journal of Solids and Structures, Vol. 9, Pg. 313-321, 1973 
22 Wang, S.S., and Yuan, F.K., "A Singular Hybrid Finite Element Analysis of Boundary-Layer Stresses in Composite Laminates,” International Journal of Solids and Structures, Vol. 19, No. 9 Pg. 825-837, 1983

23 Myers, D.E., Martin, C.J. and Blosser, M.L., "Parametric Weight Comparison of Advanced Metallic, Ceramic Tile, and Ceramic Blanket Thermal Protection Systems”, NASA TM-2000-210289, 2000 


\begin{tabular}{|l|c|}
\hline Mach Number (M) & 8.1 \\
\hline Reynold's Number (Re) & $1.0 \times 10^{6}$ \\
\hline Stagnation Temperature $\left.\mathbf{( T}_{\mathbf{0}}\right)$ & $1050 \mathrm{~K}$ \\
\hline
\end{tabular}

Table 1. Operating conditions used to study the cavity flow of a damaged TPS

\begin{tabular}{||c||c||c||c||c||}
\hline $\begin{array}{c}\mathbf{T} \\
\left({ }^{\circ} \mathbf{C}\right)\end{array}$ & $\begin{array}{c}\mathbf{C} \\
\left(\mathbf{J} / \mathbf{k g}^{\circ} \mathbf{C}\right)\end{array}$ & $\begin{array}{c}\mathbf{k} \\
\left(\mathbf{W} / \mathbf{m}^{\circ} \mathbf{C}\right)\end{array}$ & $\begin{array}{c}\mathbf{E} \\
(\mathbf{G P a})\end{array}$ & $\begin{array}{c}\boldsymbol{\alpha} \\
\left(\mathbf{1 0} \mathbf{6}^{-} /{ }^{\circ} \mathbf{C}\right)\end{array}$ \\
\hline \hline-73.2 & 787.0 & 163.0 & - & - \\
\hline-17.8 & - & - & - & 21.9 \\
\hline 21.0 & - & - & 72.4 & - \\
\hline 26.9 & 875.0 & 177.0 & - & - \\
\hline 37.8 & - & - & 72.0 & 22.6 \\
\hline 93.3 & - & - & 70.4 & 23.2 \\
\hline 126.9 & 925.0 & 186.0 & - & - \\
\hline 148.9 & - & - & 68.5 & 23.6 \\
\hline 204.4 & - & - & 64.3 & 24.0 \\
\hline 260.0 & - & - & 57.3 & 24.4 \\
\hline 315.6 & - & - & 50.5 & 24.9 \\
\hline 326.9 & 1042.0 & - & - & - \\
\hline 371.1 & - & - & - & 25.4 \\
\hline 426.7 & - & - & - & 26.0 \\
\hline 482.2 & - & - & - & 26.7 \\
\hline
\end{tabular}

$\rho=2770 \mathrm{~kg} / \mathrm{m}^{3}$

$v=0.33$

Table 2. Material properties of the underlying structure (Aluminum 2024)

\begin{tabular}{||c||c|c|c|c|c||}
\cline { 2 - 6 } \multicolumn{1}{c|}{} & \multicolumn{5}{c|}{$\mathbf{P ( P a )}$} \\
\hline \hline $\mathbf{T ~}\left({ }^{\circ} \mathbf{C}\right)$ & 10.133 & 101.33 & 1013.3 & 10133 & 101330 \\
\hline \hline-17.6 & 0.009173 & 0.01904 & 0.03081 & 0.03427 & 0.03548 \\
\hline 38.0 & 0.009865 & 0.02146 & 0.03600 & 0.04067 & 0.04223 \\
\hline 93.5 & 0.01090 & 0.02337 & 0.04154 & 0.04725 & 0.04933 \\
\hline 149.1 & 0.01263 & 0.02631 & 0.04708 & 0.05504 & 0.05711 \\
\hline 204.6 & 0.01575 & 0.02908 & 0.05244 & 0.06421 & 0.06611 \\
\hline 315.7 & 0.02077 & 0.03548 & 0.06750 & 0.08308 & 0.08533 \\
\hline 426.9 & 0.02700 & 0.04327 & 0.08654 & 0.1052 & 0.1073 \\
\hline
\end{tabular}

Table 3. Conductivity of SIP $\left(\mathrm{W} / \mathrm{m}-{ }^{\circ} \mathrm{C}\right)$ with respect to temperature and pressure 


\begin{tabular}{|c||c|}
\hline $\begin{array}{c}\mathbf{T} \\
\left({ }^{\circ} \mathbf{C}\right)\end{array}$ & $\begin{array}{c}\mathbf{C} \\
\left(\mathbf{J} / \mathbf{k g}^{\circ} \mathbf{C}\right)\end{array}$ \\
\hline-17.6 & 1306.3 \\
\hline 93.5 & 1339.8 \\
\hline 204.6 & 1402.6 \\
\hline 615.7 & 1444.5 \\
\hline
\end{tabular}

$$
\begin{aligned}
& \boldsymbol{\rho}=194 \mathrm{~kg} / \mathrm{m}^{3} \\
& \mathbf{E}=807 \mathrm{kPa} \\
& \boldsymbol{v}=0.3 \\
& \boldsymbol{\alpha}=18 \times 10^{-6} /{ }^{\circ} \mathrm{C}
\end{aligned}
$$

\begin{tabular}{|c|c|c|c|c|c|}
\hline \multirow[b]{2}{*}{$\mathrm{T}\left({ }^{\circ} \mathrm{C}\right)$} & \multicolumn{5}{|c|}{$\mathbf{P}$ (Pa) } \\
\hline & 10.133 & 101.33 & 1013.3 & 10133 & 101330 \\
\hline-17.6 & $\begin{array}{c}0.02597 \\
(0.01298)\end{array}$ & $\begin{array}{c}0.03116 \\
(0.01731)\end{array}$ & $\begin{array}{c}0.04847 \\
(0.03168)\end{array}$ & $\begin{array}{c}0.05712 \\
(0.04328)\end{array}$ & $\begin{array}{c}0.06751 \\
(0.04760)\end{array}$ \\
\hline 121.3 & $\begin{array}{c}0.03462 \\
(0.01593)\end{array}$ & $\begin{array}{c}0.03981 \\
(0.02164)\end{array}$ & $\begin{array}{c}0.05712 \\
(0.03895)\end{array}$ & $\begin{array}{c}0.07097 \\
(0.05470)\end{array}$ & $\begin{array}{c}0.08136 \\
(0.05903)\end{array}$ \\
\hline 260.2 & $\begin{array}{c}0.04501 \\
(0.02164)\end{array}$ & $\begin{array}{c}0.05193 \\
(0.02891) \\
\end{array}$ & $\begin{array}{c}0.07270 \\
(0.04778) \\
\end{array}$ & $\begin{array}{c}0.08828 \\
(0.06924) \\
\end{array}$ & $\begin{array}{c}0.09867 \\
(0.07495)\end{array}$ \\
\hline 399.1 & $\begin{array}{c}0.06059 \\
(0.03029)\end{array}$ & $\begin{array}{l}0.06924 \\
(0.3739)\end{array}$ & $\begin{array}{c}0.08828 \\
(0.05626)\end{array}$ & $\begin{array}{c}0.1108 \\
(0.08517)\end{array}$ & $\begin{array}{c}0.1212 \\
(0.09244)\end{array}$ \\
\hline 538.0 & $\begin{array}{c}0.08482 \\
(0.04033)\end{array}$ & $\begin{array}{c}0.09001 \\
(0.04760)\end{array}$ & $\begin{array}{c}0.1091 \\
(0.06786)\end{array}$ & $\begin{array}{c}0.1402 \\
(0.1039)\end{array}$ & $\begin{array}{c}0.1523 \\
(0.1139)\end{array}$ \\
\hline 676.9 & $\begin{array}{c}0.1142 \\
(0.05331)\end{array}$ & $\begin{array}{c}0.1229 \\
(0.06059)\end{array}$ & $\begin{array}{c}0.1437 \\
(0.08517)\end{array}$ & $\begin{array}{c}0.1800 \\
(0.1255)\end{array}$ & $\begin{array}{c}0.1921 \\
(0.1354)\end{array}$ \\
\hline 815.7 & $\begin{array}{c}0.1541 \\
(0.07201)\end{array}$ & $\begin{array}{c}0.1662 \\
(0.07945) \\
\end{array}$ & $\begin{array}{c}0.1887 \\
(0.1068) \\
\end{array}$ & $\begin{array}{c}0.2285 \\
(0.1515)\end{array}$ & $\begin{array}{c}0.2423 \\
(0.1631)\end{array}$ \\
\hline 954.6 & $\begin{array}{c}0.2060 \\
(0.09815)\end{array}$ & $\begin{array}{c}0.2164 \\
(0.1056)\end{array}$ & $\begin{array}{c}0.2423 \\
(0.1328)\end{array}$ & $\begin{array}{c}0.2891 \\
(0.1835)\end{array}$ & $\begin{array}{c}0.3029 \\
(0.1956)\end{array}$ \\
\hline 1093.5 & $\begin{array}{c}0.2648 \\
(0.1271) \\
\end{array}$ & $\begin{array}{c}0.2804 \\
(0.1354)\end{array}$ & $\begin{array}{c}0.3116 \\
(0.1631)\end{array}$ & $\begin{array}{c}0.3670 \\
(0.2198)\end{array}$ & $\begin{array}{c}0.3826 \\
(0.2354)\end{array}$ \\
\hline 1260.2 & $\begin{array}{c}0.3687 \\
(0.1672) \\
\end{array}$ & $\begin{array}{c}0.3826 \\
(0.1766) \\
\end{array}$ & $\begin{array}{c}0.4154 \\
(0.2008) \\
\end{array}$ & $\begin{array}{c}0.4726 \\
(0.2683) \\
\end{array}$ & $\begin{array}{c}0.4985 \\
(0.2891) \\
\end{array}$ \\
\hline 1371.3 & $\begin{array}{c}- \\
(0.2008)\end{array}$ & $\begin{array}{c}- \\
(0.2129)\end{array}$ & $\begin{array}{c}- \\
(0.2406)\end{array}$ & $\begin{array}{c}- \\
(0.3098)\end{array}$ & $\begin{array}{c}- \\
(0.3358)\end{array}$ \\
\hline 1538.0 & $\begin{array}{c}- \\
(0.2666)\end{array}$ & $\begin{array}{c}- \\
(0.2804)\end{array}$ & $\begin{array}{c}- \\
(0.3116)\end{array}$ & $\begin{array}{c}- \\
(0.3843)\end{array}$ & $\begin{array}{c}- \\
(0.4189)\end{array}$ \\
\hline 1649.1 & $\begin{array}{c}- \\
(0.3289)\end{array}$ & $\begin{array}{c}- \\
(0.3393) \\
\end{array}$ & $\begin{array}{c}- \\
(0.3791)\end{array}$ & $\begin{array}{c}- \\
(0.4535) \\
\end{array}$ & $\begin{array}{c}- \\
(0.5020) \\
\end{array}$ \\
\hline
\end{tabular}

Table 4. Material properties of SIP

Table 5. Conductivity of LI-900 tile $\left(\mathrm{W} / \mathrm{m}-{ }^{\circ} \mathrm{C}\right)$ with respect to temperature and pressure 


\begin{tabular}{||c||c||c||}
\hline $\begin{array}{c}\mathbf{T} \\
\left({ }^{\circ} \mathbf{C}\right)\end{array}$ & $\begin{array}{c}\mathbf{C} \\
\left(\mathbf{J} / \mathbf{k g}^{\circ} \mathbf{C}\right)\end{array}$ & $\begin{array}{c}\boldsymbol{\alpha} \\
\left(\mathbf{1 0}^{\mathbf{6}} /{ }^{\circ} \mathbf{C}\right)\end{array}$ \\
\hline \hline-17.6 & 628.0 & 0.405 \\
\hline 121.3 & 879.2 & 0.540 \\
\hline 260.2 & 1055.1 & 0.648 \\
\hline 399.1 & 1151.4 & 0.720 \\
\hline 538.0 & 1205.8 & 0.792 \\
\hline 676.9 & 1239.3 & 0.576 \\
\hline 815.7 & 1256.0 & 0.480 \\
\hline 926.9 & 1264.4 & 0.432 \\
\hline 954.6 & 1268.6 & - \\
\hline 1093.5 & - & 0.360 \\
\hline
\end{tabular}

$\begin{array}{llll}\boldsymbol{\rho} & =194 & \mathrm{~kg} / \mathrm{m}^{3} \\ \mathbf{E}_{\mathrm{x}}, \mathbf{E}_{\mathrm{z}} & =172.4 \mathrm{MPa} \\ \mathbf{E}_{\mathrm{y}} & =48.3 \mathrm{MPa} \\ \mathbf{G}_{\mathrm{xy}}, \mathbf{G}_{\mathrm{yz}} & =20.7 & \mathrm{MPa} \\ \mathbf{G}_{\mathrm{xz}} & =72.4 & \mathrm{MPa} \\ \boldsymbol{v}_{\mathrm{xy}} & =0.16 & \\ \boldsymbol{v}_{\mathrm{xz}} & =0.18 \\ \boldsymbol{v}_{\mathrm{yz}} & =0.04 & \end{array}$

Table 6. Material properties of LI-900 tiles

\begin{tabular}{||l||c||c||}
\cline { 2 - 3 } \multicolumn{1}{c||}{} & Previous assumption & Improved assumption \\
\hline \hline $\begin{array}{l}\text { 1)Emissivity of damaged surface of } \\
\text { LI-900 tile }\end{array}$ & $\begin{array}{c}\text { Same constant emissivity } \\
\text { as undamaged surface }\end{array}$ & $\begin{array}{c}\text { Emissivity is a function of } \\
\text { temperature (Table 8) }\end{array}$ \\
\hline 3) Conductivities of tile and SIP & $\begin{array}{c}\text { Conductivities are } \\
\text { functions of temperature } \\
\text { only. }\end{array}$ & $\begin{array}{c}\text { Conductivities are functions of both } \\
\text { temperature and pressure }\end{array}$ \\
\hline 4) Mechanical properties & Isotropic & $\begin{array}{c}\text { Transversely isotropic (In-plane } \\
\text { properties differ from out-of-plane } \\
\text { properties }\end{array}$ \\
\hline
\end{tabular}

Table 7. Summary of the differences in material properties between previous and improved assumptions

\begin{tabular}{|c||c||}
\hline Temperature $\left.{ }^{\circ}{ }^{\circ} \mathbf{C}\right)$ & Emissivity of Uncoated LI-900 Tile \\
\hline 27 & 0.88050 \\
\hline 127 & 0.83613 \\
\hline 227 & 0.76578 \\
\hline 327 & 0.68410 \\
\hline 427 & 0.60390 \\
\hline 527 & 0.53177 \\
\hline 627 & 0.46981 \\
\hline 727 & 0.41785 \\
\hline 827 & 0.37477 \\
\hline 927 & 0.33918 \\
\hline 1027 & 0.30980 \\
\hline 1127 & 0.28548 \\
\hline 1227 & 0.26527 \\
\hline 1327 & 0.24841 \\
\hline
\end{tabular}

Table 8. Emissivity of uncoated tile with respect to temperature 


\begin{tabular}{|c|c|c|c|c|c|c|c|}
\hline $\begin{array}{c}\text { TPS } \\
\text { component }\end{array}$ & $\begin{array}{c}D \\
\text { (inch) }\end{array}$ & \multicolumn{2}{|c|}{$\begin{array}{c}\text { Temperature } \\
\left({ }^{\circ} \mathrm{C}\right)\end{array}$} & \multicolumn{2}{|c|}{ \% change } & \multicolumn{2}{|c|}{$\begin{array}{c}\text { Time } \\
\text { (s) }\end{array}$} \\
\hline \multirow{4}{*}{ Tile } & 0 & \multicolumn{2}{|c|}{981} & \multicolumn{2}{|c|}{ NA } & \multicolumn{2}{|c|}{850} \\
\hline & 0.5 & 981 & 1457 & 0 & 48.5 & 850 & 850 \\
\hline & 1.0 & 981 & 1499 & 0 & 52.8 & 850 & 850 \\
\hline & 1.5 & 981 & 1515 & 0 & 54.4 & 850 & 850 \\
\hline \multirow{4}{*}{ SIP } & 0 & \multicolumn{2}{|c|}{150} & \multicolumn{2}{|c|}{ NA } & \multicolumn{2}{|c|}{6600} \\
\hline & 0.5 & 149 & 156 & -0.7 & 4.0 & 6550 & 6550 \\
\hline & 1.0 & 145 & 180 & -3.3 & 20.0 & 6450 & 6300 \\
\hline & 1.5 & 139 & 225 & -7.3 & 50.0 & 6250 & 5800 \\
\hline \multirow{4}{*}{$\begin{array}{c}\text { Underlying } \\
\text { structure }\end{array}$} & 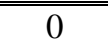 & \multicolumn{2}{|c|}{ 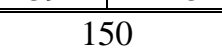 } & \multicolumn{2}{|c|}{ NA } & \multicolumn{2}{|c|}{ 7150 } \\
\hline & 0.5 & 148 & 156 & -1.3 & 4.0 & 7150 & 7100 \\
\hline & 1.0 & 144 & 179 & -4.0 & 19.3 & 7100 & 6850 \\
\hline & 1.5 & 138 & 224 & -8.0 & 49.3 & 6900 & 6300 \\
\hline
\end{tabular}

Table 9. Maximum temperatures results for all TPS component of the square configurations from Ref. 13

\begin{tabular}{|c|c|c|c|c|c|c|c|}
\hline $\begin{array}{c}\text { TPS } \\
\text { component }\end{array}$ & $\begin{array}{c}D \\
\text { (inch) }\end{array}$ & \multicolumn{2}{|c|}{$\begin{array}{c}\text { Temperature } \\
\left({ }^{\circ} \mathrm{C}\right)\end{array}$} & \multicolumn{2}{|c|}{ \% change } & \multicolumn{2}{|c|}{$\begin{array}{c}\text { Time } \\
\text { (s) }\end{array}$} \\
\hline \multirow{4}{*}{ Tile } & 0 & \multicolumn{2}{|c|}{981} & \multicolumn{2}{|c|}{ NA } & \multicolumn{2}{|c|}{850} \\
\hline & 0.5 & 981 & 1846 & 0 & 88.2 & 850 & 850 \\
\hline & 1.0 & 981 & 2048 & 0 & 108.8 & 850 & 850 \\
\hline & 1.5 & 981 & 2133 & 0 & 117.4 & 850 & 850 \\
\hline \multirow{4}{*}{ SIP } & 0 & \multicolumn{2}{|c|}{150} & \multicolumn{2}{|c|}{ NA } & \multicolumn{2}{|c|}{5000} \\
\hline & 0.5 & 148 & 167 & -1.3 & 11.3 & 5000 & 4900 \\
\hline & 1.0 & 145 & 242 & -3.3 & 61.3 & 4900 & 4550 \\
\hline & 1.5 & 140 & 382 & -6.7 & 154.7 & 4750 & 3900 \\
\hline \multirow{4}{*}{$\begin{array}{l}\text { Underlying } \\
\text { structure }\end{array}$} & 0 & \multicolumn{2}{|c|}{150} & \multicolumn{2}{|c|}{ NA } & \multicolumn{2}{|c|}{5450} \\
\hline & 0.5 & 148 & 166 & -1.3 & 10.7 & 5450 & 5350 \\
\hline & 1.0 & 144 & 241 & -4.0 & 60.7 & 5400 & 4950 \\
\hline & 1.5 & 139 & 380 & -7.3 & 153.3 & 5300 & 4200 \\
\hline
\end{tabular}

Table 10. Maximum temperatures results for all TPS component of the square configurations using new assumptions

\begin{tabular}{|c|c|c|c|c|c|c|c|}
\hline \multirow{2}{*}{$\begin{array}{l}\text { Thermal } \\
\text { Loading }\end{array}$} & \multirow{2}{*}{$\begin{array}{c}D \\
\text { (inch) }\end{array}$} & \multicolumn{2}{|c|}{$\begin{array}{c}\text { Max. von Mises stress } \\
\text { (kPa) }\end{array}$} & \multicolumn{2}{|c|}{ \% change } & \multicolumn{2}{|c|}{$\begin{array}{c}\text { Time } \\
\text { (s) }\end{array}$} \\
\hline & & BC1 & BC2 & BC1 & BC2 & BC1 & BC2 \\
\hline \multirow{4}{*}{$q_{1}$} & 0 & 63.4 & 63.6 & NA & NA & 350 & 350 \\
\hline & 0.5 & 111.2 & 111.6 & 75.4 & 75.5 & 350 & 350 \\
\hline & 1.0 & 99.5 & 99.9 & 56.9 & 57.1 & 400 & 400 \\
\hline & 1.5 & 96.4 & 96.8 & 52.1 & 52.2 & 400 & 400 \\
\hline \multirow{4}{*}{$q_{2}$} & 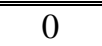 & 63.4 & (63.6 & NA & NA & 350 & 350 \\
\hline & 0.5 & 138.1 & 138.3 & 117.8 & 117.5 & 400 & 400 \\
\hline & 1.0 & 136.8 & 137.1 & 115.8 & 115.6 & 400 & 400 \\
\hline & 1.5 & 149.9 & 150.0 & 136.4 & 135.8 & 400 & 400 \\
\hline
\end{tabular}

Table 11. Maximum von Mises stresses and times at which they occur in tile for the square configurations using previous assumptions 


\begin{tabular}{|c|c|c|c|c|c|c|c|}
\hline \multirow{2}{*}{$\begin{array}{l}\text { Thermal } \\
\text { Loading }\end{array}$} & \multirow[t]{2}{*}{$\begin{array}{c}D \\
\text { (inch) }\end{array}$} & \multicolumn{2}{|c|}{$\begin{array}{c}\text { Max. von Mises stress } \\
\text { (kPa) }\end{array}$} & \multicolumn{2}{|c|}{$\%$ change } & \multicolumn{2}{|c|}{$\begin{array}{c}\text { Time } \\
\text { (s) }\end{array}$} \\
\hline & & BC1 & BC2 & BC1 & BC2 & BC1 & BC2 \\
\hline \multirow{4}{*}{$q_{1}$} & 0 & 30.1 & 4.61 & NA & NA & 7150 & 6050 \\
\hline & 0.5 & 30.0 & 4.31 & -0.3 & -6.5 & 7250 & 5600 \\
\hline & 1.0 & 29.0 & 4.20 & -3.7 & -8.9 & 7200 & 5450 \\
\hline & 1.5 & 27.6 & 3.94 & -8.3 & -14.5 & 7000 & 5150 \\
\hline \multirow{4}{*}{$q_{2}$} & 0 & 30.1 & 4.61 & NA & NA & 7150 & 6050 \\
\hline & 0.5 & 31.8 & 4.65 & 5.6 & 0.9 & 7200 & 5900 \\
\hline & 1.0 & 37.3 & 5.45 & 23.9 & 18.2 & 6800 & 5700 \\
\hline & 1.5 & 47.7 & 6.99 & 58.5 & 51.6 & 6350 & 5250 \\
\hline
\end{tabular}

Table 12. Maximum von Mises stresses and times at which they occur in SIP for the square configurations using previous assumptions

\begin{tabular}{|c|c|c|c|c|c|c|c|}
\hline \multirow{2}{*}{$\begin{array}{l}\text { Thermal } \\
\text { Loading }\end{array}$} & \multirow{2}{*}{$\begin{array}{c}D \\
\text { (inch) }\end{array}$} & \multicolumn{2}{|c|}{$\begin{array}{c}\text { Max. von Mises stress } \\
\text { (MPa) }\end{array}$} & \multicolumn{2}{|c|}{ \% change } & \multicolumn{2}{|c|}{$\begin{array}{c}\text { Time } \\
\text { (s) }\end{array}$} \\
\hline & & BC1 & BC2 & BC1 & BC2 & BC1 & BC2 \\
\hline \multirow{4}{*}{$q_{1}$} & 0 & 2.32 & 283.1 & NA & NA & 7300 & 7150 \\
\hline & 0.5 & 2.34 & 277.9 & 0.8 & -1.8 & 7300 & 7150 \\
\hline & 1.0 & 2.26 & 268.6 & -2.6 & -5.1 & 7250 & 7100 \\
\hline & 1.5 & 2.16 & 255.5 & -6.9 & -9.7 & 7100 & 6900 \\
\hline \multirow{4}{*}{$q_{2}$} & 0 & 2.32 & 283.1 & NA & NA & 7300 & 7150 \\
\hline & 0.5 & 2.48 & 294.6 & 6.9 & 4.1 & 7300 & 7100 \\
\hline & 1.0 & 2.91 & 345.5 & 25.4 & 22.0 & 6900 & 6850 \\
\hline & 1.5 & 3.73 & 442.3 & 60.8 & 56.2 & 6450 & 6300 \\
\hline
\end{tabular}

Table 13. Maximum von Mises stresses and times at which they occur in underlying structure for the square configurations using previous assumptions

\begin{tabular}{|c|c|c|c|c|c|c|c|}
\hline \multirow{2}{*}{$\begin{array}{l}\text { Thermal } \\
\text { Loading }\end{array}$} & \multirow{2}{*}{$\begin{array}{c}D \\
\text { (inch) }\end{array}$} & \multicolumn{2}{|c|}{$\begin{array}{c}\text { Max. von Mises stress } \\
(\mathbf{k P a})\end{array}$} & \multicolumn{2}{|c|}{ \% change } & \multicolumn{2}{|c|}{$\begin{array}{c}\text { Time } \\
\text { (s) }\end{array}$} \\
\hline & & BC1 & BC2 & BC1 & BC2 & BC1 & BC2 \\
\hline \multirow{4}{*}{$q_{1}$} & 0 & 64.9 & 65.0 & NA & NA & 200 & 200 \\
\hline & 0.5 & 111.7 & 112.0 & 72.1 & 72.3 & 250 & 250 \\
\hline & 1.0 & 105.3 & 105.5 & 62.2 & 62.3 & 250 & 250 \\
\hline & 1.5 & 96.3 & 96.5 & 48.4 & 48.5 & 250 & 250 \\
\hline \multirow{4}{*}{$q_{2}$} & 0 & 64.9 & 65.0 & NA & NA & 200 & 200 \\
\hline & 0.5 & 96.4 & 96.6 & 48.5 & 48.6 & 400 & 400 \\
\hline & 1.0 & 119.1 & 119.3 & 83.5 & 83.5 & 400 & 400 \\
\hline & 1.5 & 132.2 & 132.4 & 103.7 & 103.7 & 400 & 400 \\
\hline
\end{tabular}

Table 14. Maximum von Mises stresses and times at which they occur in tile for the square configurations using new assumptions 


\begin{tabular}{|c|c|c|c|c|c|c|c|}
\hline \multirow{2}{*}{$\begin{array}{l}\text { Thermal } \\
\text { Loading }\end{array}$} & \multirow[t]{2}{*}{$\begin{array}{c}D \\
\text { (inch) }\end{array}$} & \multicolumn{2}{|c|}{$\begin{array}{c}\text { Max. von Mises stress } \\
(\mathbf{k P a})\end{array}$} & \multicolumn{2}{|c|}{ \% change } & \multicolumn{2}{|c|}{$\begin{array}{c}\text { Time } \\
\text { (s) }\end{array}$} \\
\hline & & BC1 & BC2 & BC1 & BC2 & BC1 & BC2 \\
\hline \multirow{4}{*}{$q_{1}$} & 0 & 32.2 & 3.08 & NA & NA & 5450 & 5500 \\
\hline & 0.5 & 31.9 & 3.05 & -0.9 & -1.0 & 5450 & 5500 \\
\hline & 1.0 & 30.9 & 2.96 & -4.0 & -3.9 & 5400 & 5450 \\
\hline & 1.5 & 29.5 & 2.85 & -8.4 & -7.5 & 5300 & 5350 \\
\hline \multirow{4}{*}{$q_{2}$} & 0 & 32.2 & 3.08 & NA & NA & 5450 & 5500 \\
\hline & 0.5 & 36.8 & 3.51 & 14.3 & 14.0 & 5350 & 5400 \\
\hline & 1.0 & 56.7 & 5.38 & 76.1 & 74.7 & 4950 & 5000 \\
\hline & 1.5 & 96.7 & 8.89 & 200.3 & 188.6 & 4200 & 4250 \\
\hline
\end{tabular}

Table 15. Maximum von Mises stresses and times at which they occur in SIP for the square configurations using new assumptions

\begin{tabular}{|c|c|c|c|c|c|c|c|}
\hline \multirow{2}{*}{$\begin{array}{l}\text { Thermal } \\
\text { Loading }\end{array}$} & \multirow{2}{*}{$\begin{array}{c}D \\
\text { (inch) }\end{array}$} & \multicolumn{2}{|c|}{$\begin{array}{c}\text { Max. von Mises stress } \\
\text { (MPa) }\end{array}$} & \multicolumn{2}{|c|}{ \% change } & \multicolumn{2}{|c|}{$\begin{array}{c}\text { Time } \\
\text { (s) }\end{array}$} \\
\hline & & BC1 & BC2 & BC1 & BC2 & BC1 & BC2 \\
\hline \multirow{4}{*}{$q_{1}$} & 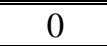 & 1.86 & 308.9 & NA & NA & 5550 & 5450 \\
\hline & 0.5 & 1.84 & 305.9 & -1.1 & -1.0 & 5550 & 5450 \\
\hline & 1.0 & 1.79 & 297.0 & -3.8 & -3.9 & 5500 & 5400 \\
\hline & 1.5 & 1.72 & 284.9 & -7.5 & -7.8 & 5400 & 5300 \\
\hline \multirow{4}{*}{$q_{2}$} & 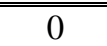 & 1.86 & 308.9 & NA & NA & 5550 & 25450 \\
\hline & 0.5 & 2.11 & 347.0 & 13.4 & 12.3 & 5450 & 5350 \\
\hline & 1.0 & 3.09 & 476.5 & 66.1 & 54.3 & 5050 & 4950 \\
\hline & 1.5 & 4.88 & 688.8 & 162.4 & 123.0 & 4250 & 4200 \\
\hline
\end{tabular}

Table 16. Maximum von Mises stresses and times at which they occur in underlying structure for the square configurations using new assumptions

\begin{tabular}{|c|c|c|c|c|c|c|c|}
\hline $\begin{array}{c}\text { TPS } \\
\text { component }\end{array}$ & $\begin{array}{c}D \\
\text { (inch) }\end{array}$ & \multicolumn{2}{|c|}{$\begin{array}{c}\text { Temperature } \\
\left({ }^{\circ} \mathrm{C}\right)\end{array}$} & \multicolumn{2}{|c|}{$\%$ change } & \multicolumn{2}{|c|}{$\begin{array}{c}\text { Time } \\
\text { (s) }\end{array}$} \\
\hline \multirow{4}{*}{ Tile } & 0 & \multicolumn{2}{|c|}{981} & \multicolumn{2}{|c|}{ NA } & \multicolumn{2}{|c|}{850} \\
\hline & 0.5 & 1703 & 1940 & 73.6 & 97.8 & 850 & 850 \\
\hline & 1.0 & 1898 & 2171 & 93.5 & 121.3 & 850 & 850 \\
\hline & 1.5 & 2080 & 2313 & 112.0 & 135.8 & 850 & 850 \\
\hline \multirow{4}{*}{ SIP } & 0 & \multicolumn{2}{|c|}{150} & \multicolumn{2}{|c|}{ NA } & \multicolumn{2}{|c|}{5000} \\
\hline & 0.5 & 153 & 160 & 2.0 & 6.7 & 4950 & 4950 \\
\hline & 1.0 & 173 & 206 & 15.3 & 37.3 & 4850 & 4700 \\
\hline & 1.5 & 215 & 302 & 43.3 & 101.3 & 4450 & 4150 \\
\hline \multirow{4}{*}{$\begin{array}{l}\text { Underlying } \\
\text { structure }\end{array}$} & 0 & \multicolumn{2}{|c|}{150} & \multicolumn{2}{|c|}{ NA } & \multicolumn{2}{|c|}{5450} \\
\hline & 0.5 & 153 & 159 & 2.0 & 6.0 & 5400 & 5450 \\
\hline & 1.0 & 172 & 205 & 14.7 & 36.7 & 5250 & 5100 \\
\hline & 1.5 & 213 & 300 & 42.0 & 100.0 & 4900 & 4500 \\
\hline
\end{tabular}

CFL3D - bold

EP - italics

Table 17. Maximum temperatures results for all TPS components subjected to flow dependent heat loads 


\begin{tabular}{|c|c|c|c|c|c|c|c|}
\hline $\begin{array}{c}\text { TPS } \\
\text { component } \\
\end{array}$ & $\begin{array}{c}D \\
\text { (inch) }\end{array}$ & \multicolumn{2}{|c|}{$\begin{array}{c}\text { Max. von Mises stress } \\
(\mathbf{k P a})\end{array}$} & \multicolumn{2}{|c|}{ \% change } & \multicolumn{2}{|c|}{$\begin{array}{c}\text { Time } \\
\text { (s) }\end{array}$} \\
\hline \multirow{4}{*}{ Tile } & 0 & \multicolumn{2}{|c|}{65.0} & \multicolumn{2}{|c|}{ NA } & \multicolumn{2}{|c|}{200} \\
\hline & 0.5 & 142.9 & 154.3 & 119.8 & 137.4 & 400 & 400 \\
\hline & 1.0 & 134.2 & 159.0 & 106.5 & 144.6 & 350 & 450 \\
\hline & 1.5 & 129.2 & 178.0 & 98.8 & 173.8 & 350 & 450 \\
\hline \multirow{4}{*}{ SIP } & 0 & \multicolumn{2}{|c|}{3.08} & \multicolumn{2}{|c|}{ NA } & \multicolumn{2}{|c|}{5500} \\
\hline & 0.5 & 3.25 & 3.41 & 5.5 & 10.7 & 5450 & 5400 \\
\hline & 1.0 & 3.72 & 4.53 & 20.8 & 47.1 & 5300 & 5150 \\
\hline & 1.5 & 4.71 & 6.81 & 52.9 & 121.1 & 4950 & 4550 \\
\hline \multirow{4}{*}{$\begin{array}{l}\text { Underlying } \\
\text { structure }\end{array}$} & 0 & \multicolumn{2}{|c|}{309,000} & \multicolumn{2}{|c|}{ NA } & \multicolumn{2}{|c|}{5450} \\
\hline & 0.5 & 287,000 & 302,000 & -7.1 & -2.3 & 5400 & 5400 \\
\hline & 1.0 & 329,000 & 403,000 & 6.5 & 30.4 & 5250 & 5100 \\
\hline & 1.5 & 420,000 & 608,000 & 35.9 & 96.8 & 4900 & 4500 \\
\hline
\end{tabular}

CFL3D - bold

EP - italics

Table 18. Maximum von Mises Stress for all TPS components subjected to flow dependent heat loads and BC2 boundary condition

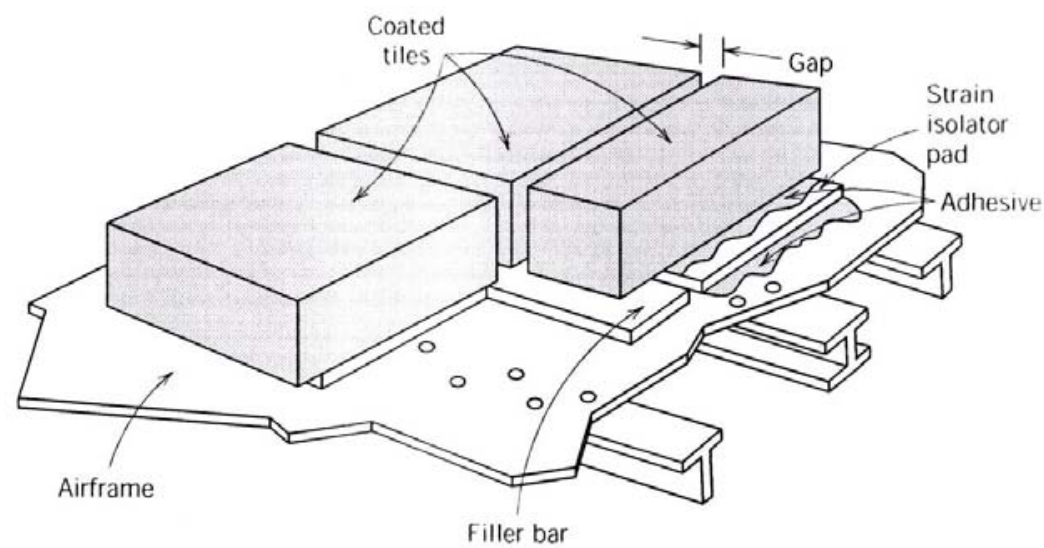

Figure 1. Space Shuttle TPS and Airframe (Callister, W.D., "Materials Science and Engineering: An introduction”, John Wiley and Sons Inc., New York, 2003, Pg. S-349)

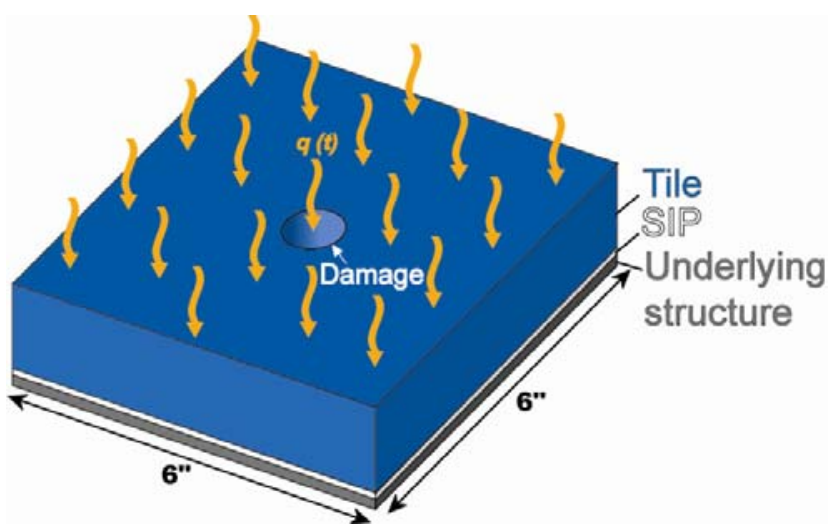

Figure 2. Schematic view of square segment of the three-layered TPS configuration 


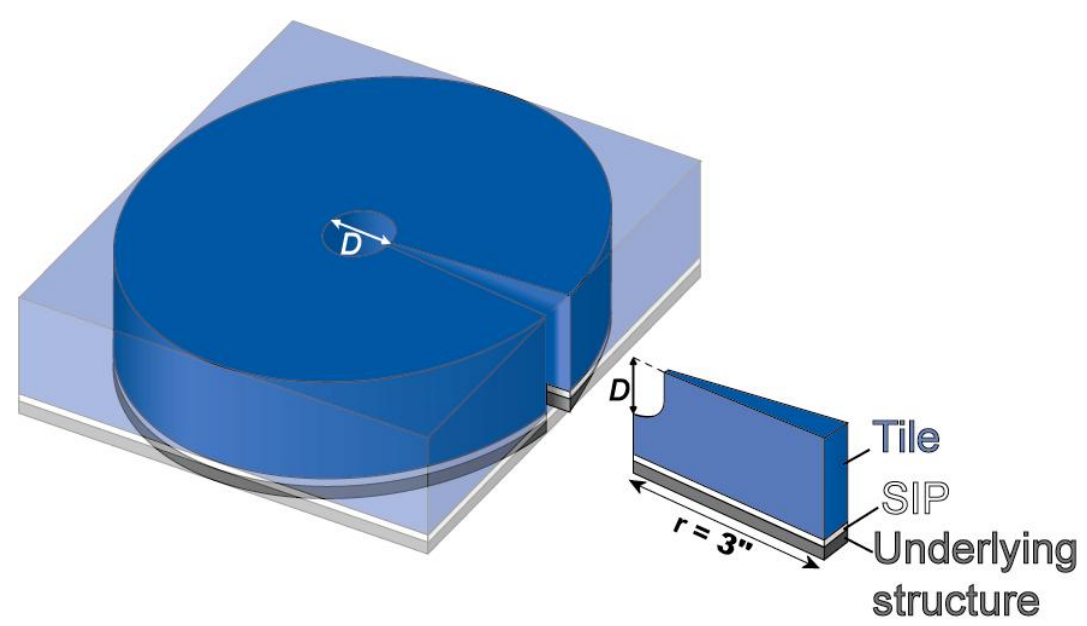

Figure 3. Circular axisymmetric configuration

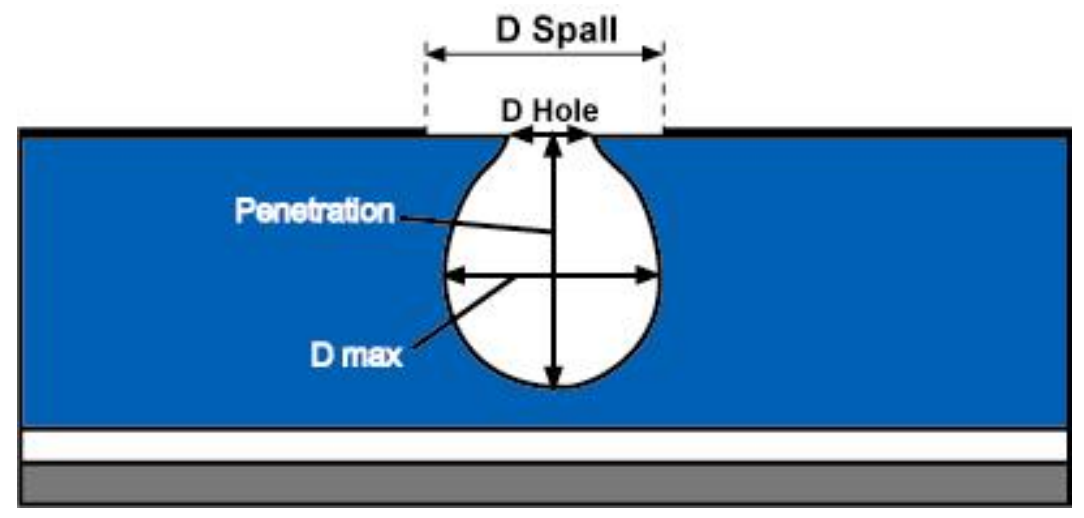

Figure 4. Damage geometry associated with hypervelocity impact.

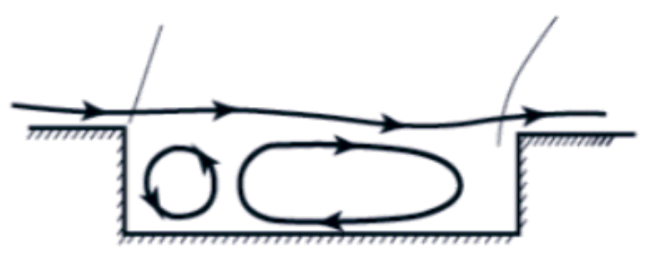

Open Cavity

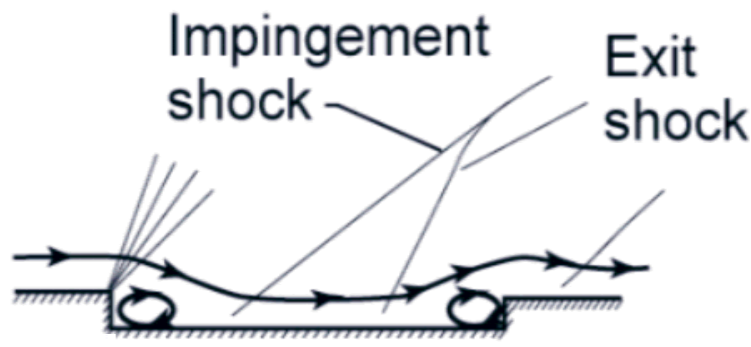

Closed Cavity

Figure 5. Different types of supersonic/hypersonic cavity flows. 


\section{Flow Direction}
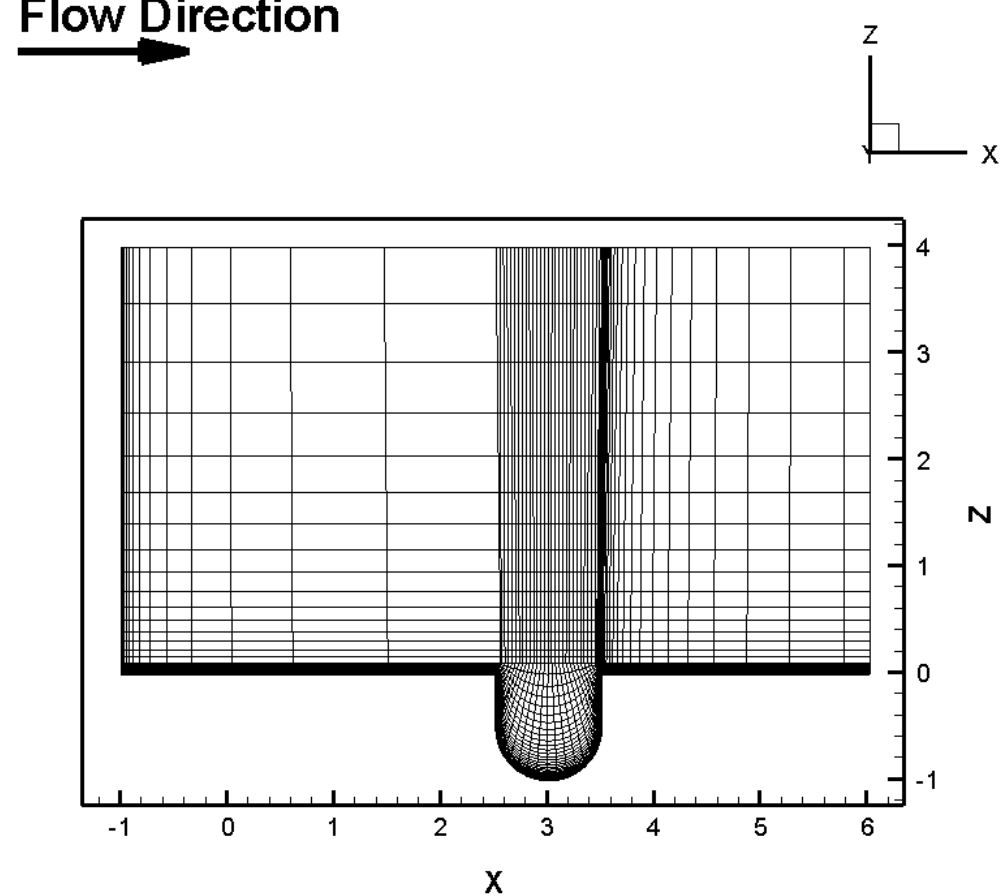

Figure 6. Coarsened view of CFL3D computational domain for the damaged tile.

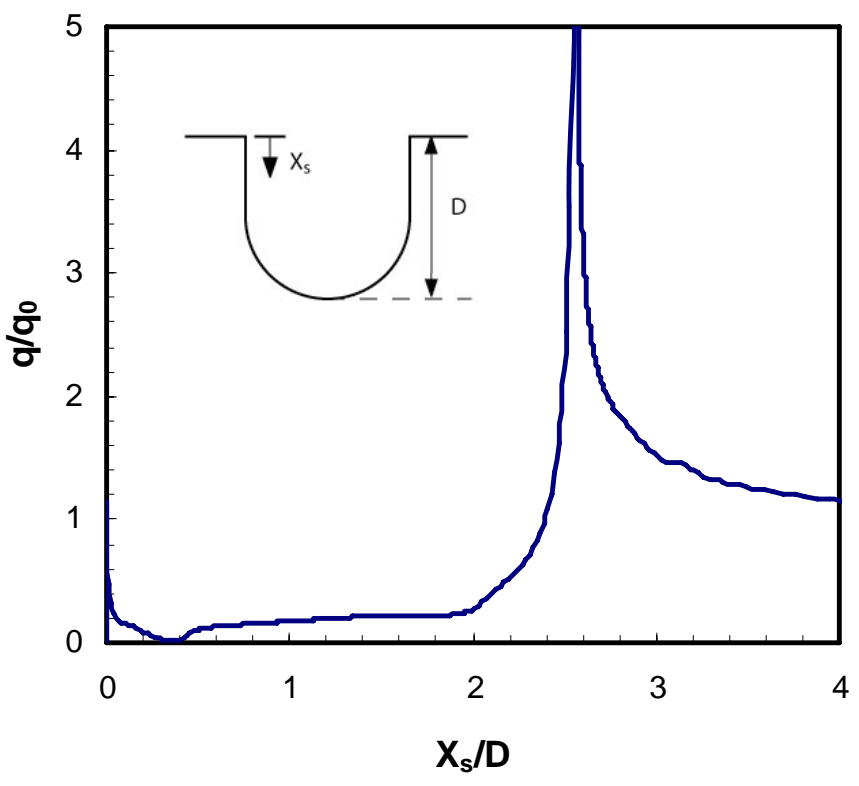

Figure 7. Heat load ratio along damaged surface from CFL3D analysis 


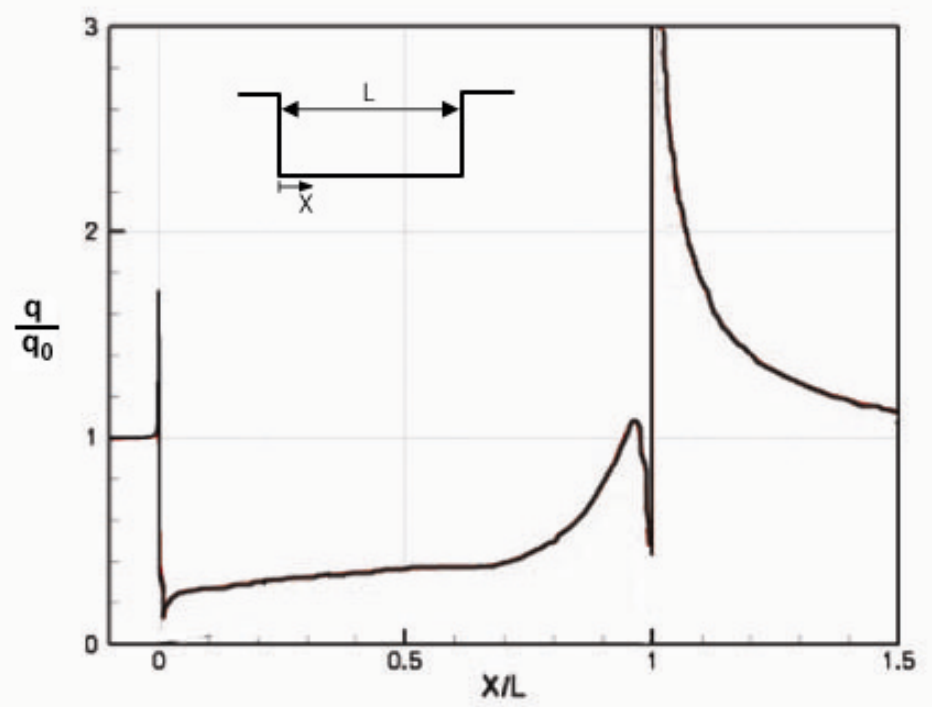

Figure 8. Heat load ratio profile from Ref. 18

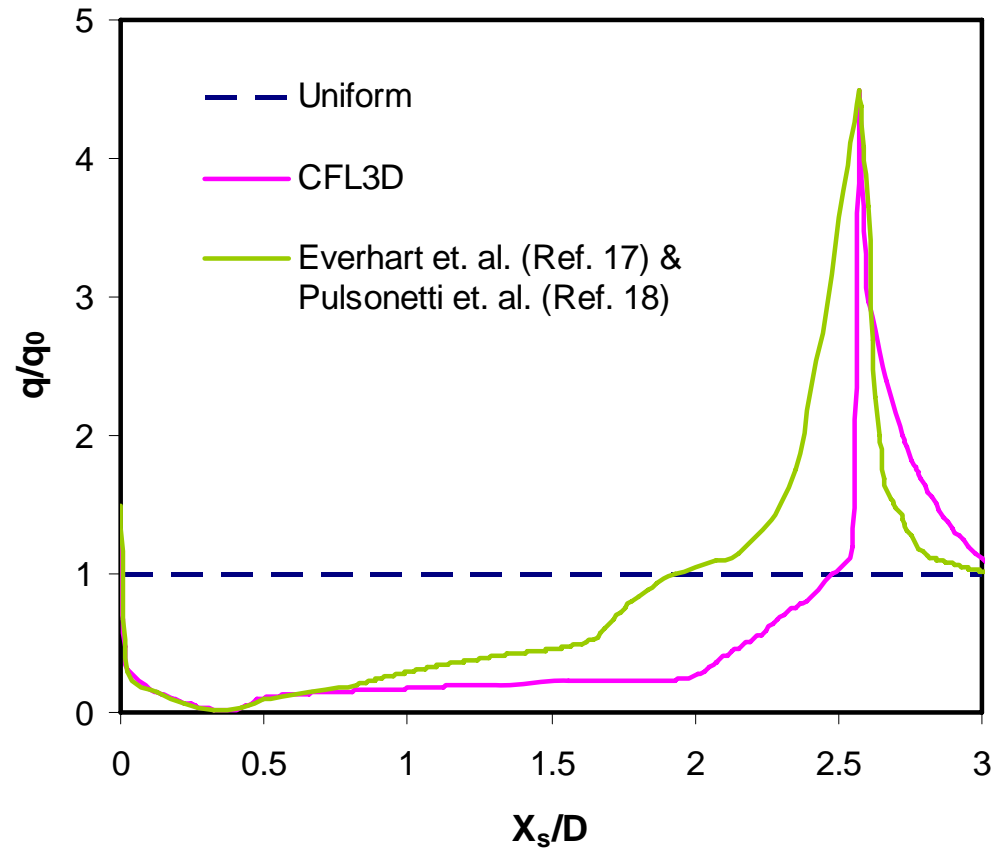

Figure 9. Heat load ratio profiles based on CFL3D and published data 


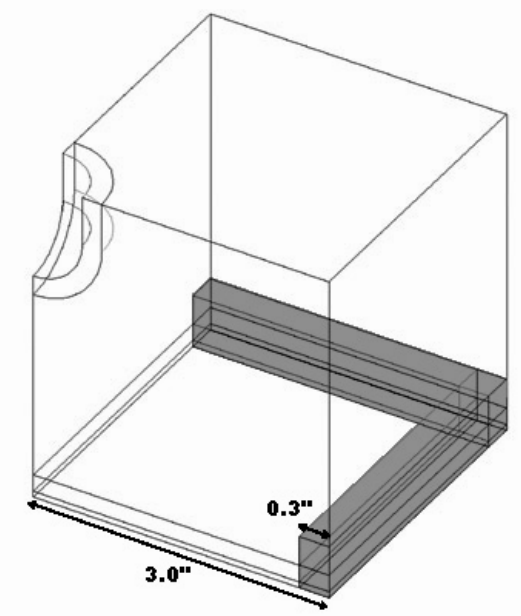

Figure 10. Square configuration illustrating the boundary layer region for the thermal stress analysis

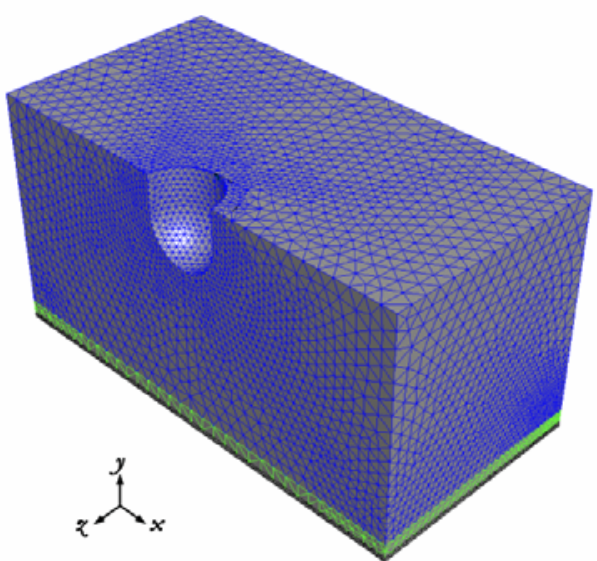

(a) Square configuration for $D=1$ ” damage system

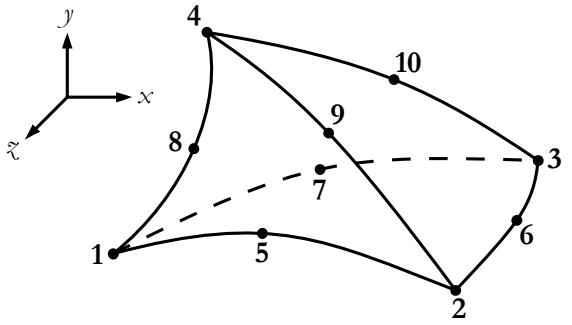

(b) 10 node quadratic tetrahedron element used for square configuration

Figure 11. Schematic representation of the square configuration

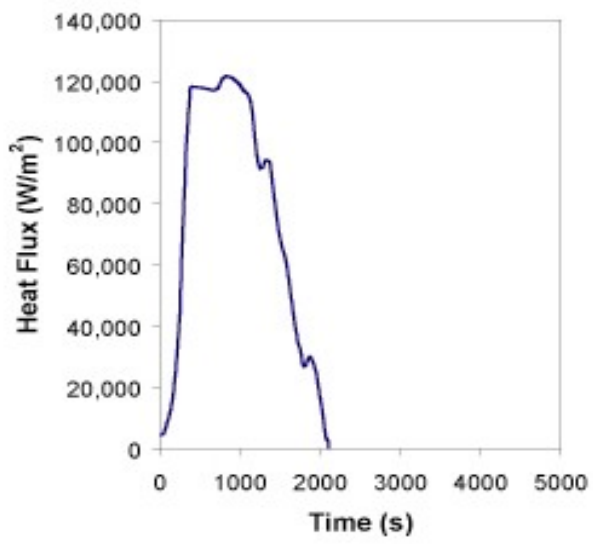

Figure 12. Re-entry heat load loading profile for the ATS vehicle, $q_{\text {ATS }}$ 


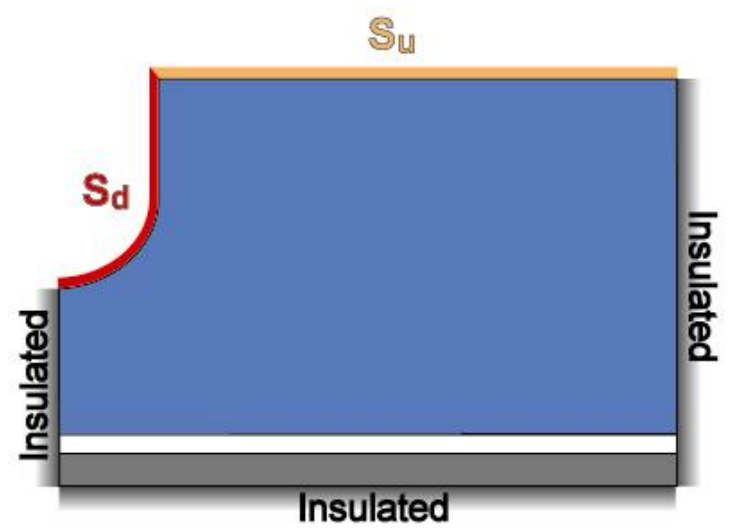

Figure 13. Cross section of TPS showing the undamaged and damaged surfaces subjected to uniform heat loads

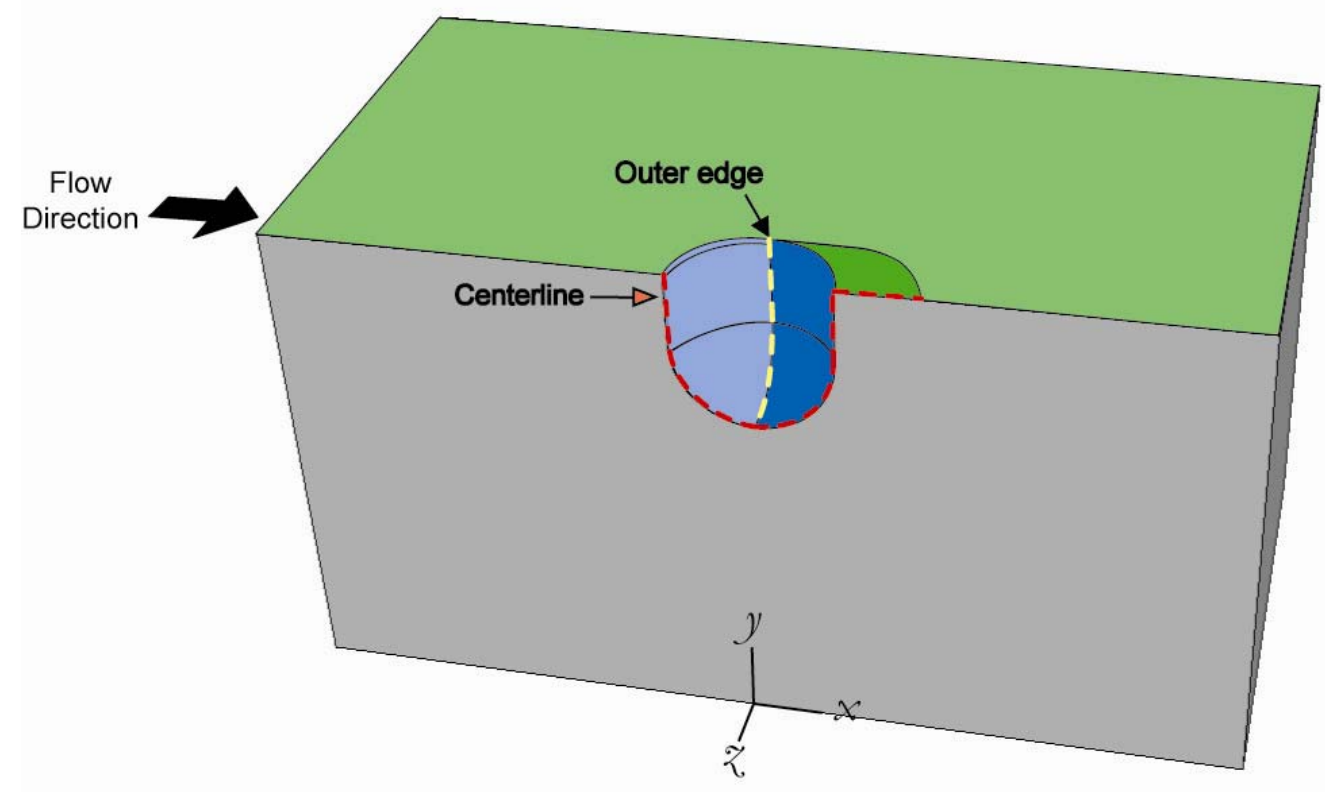

Figure 14. Half model of square configuration showing the different sections required for the application of the flow dependent heat load 

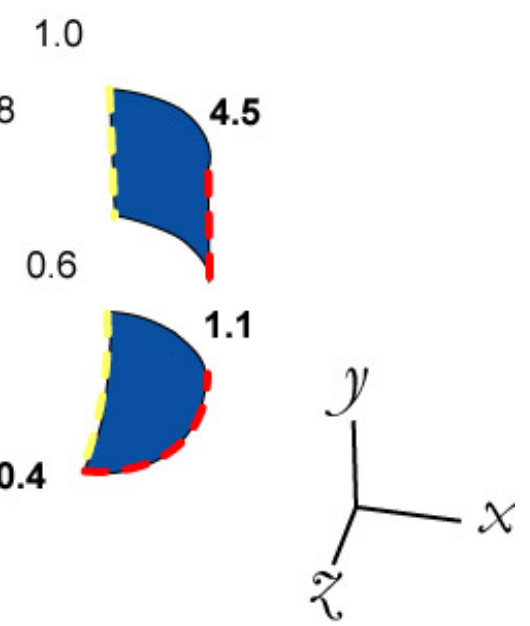

(a) Heat load ratios at corners of subsections

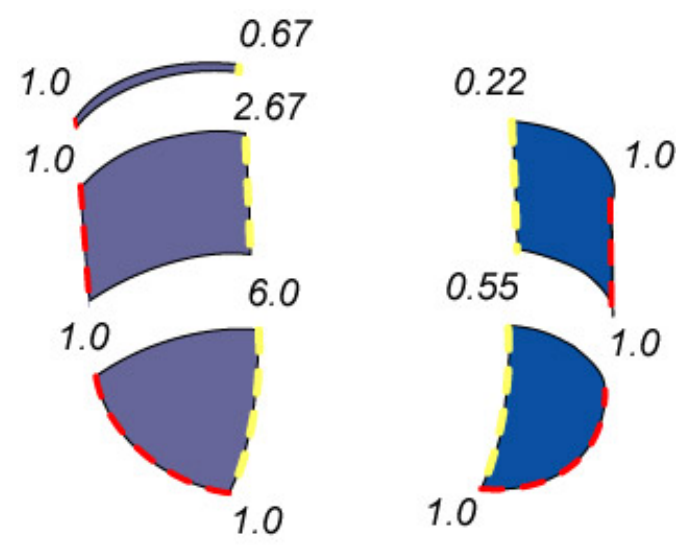

(b) Values for calculating coefficients of Equation (3)

Figure 15. Schematic of sub-sections of damaged surface.

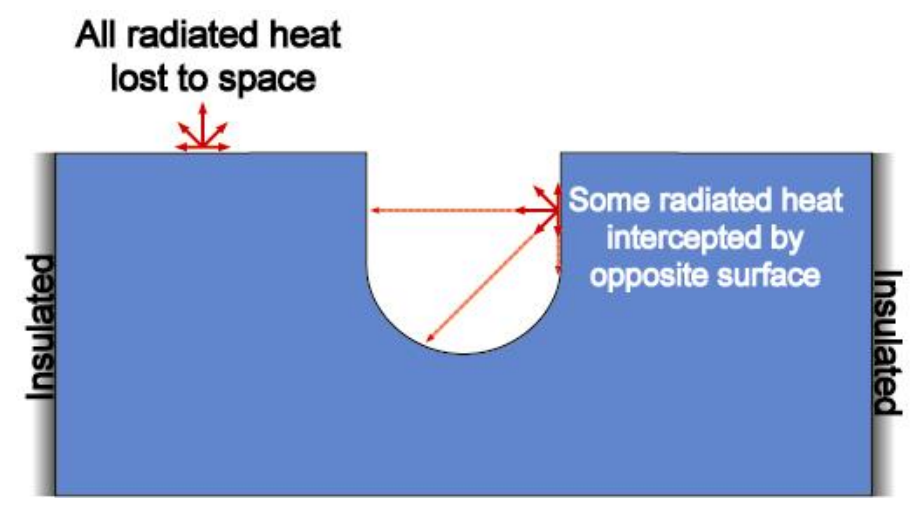

Figure 16. Schematic representation of radiation heat loss in the tile

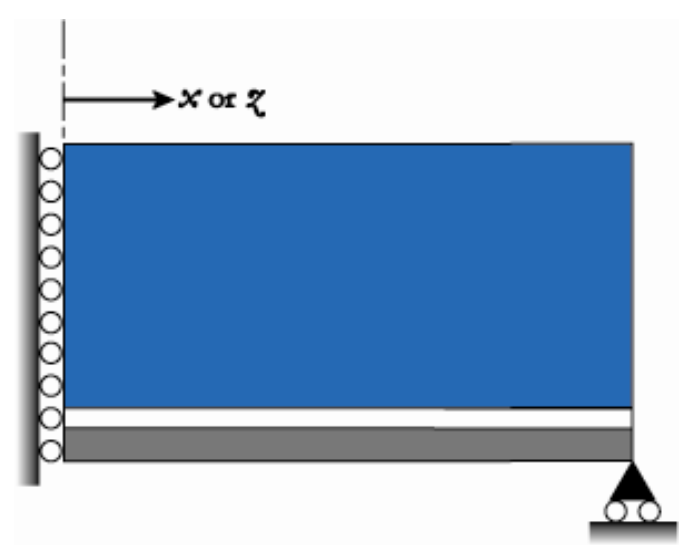

(a) unrestrained boundary condition, BC1

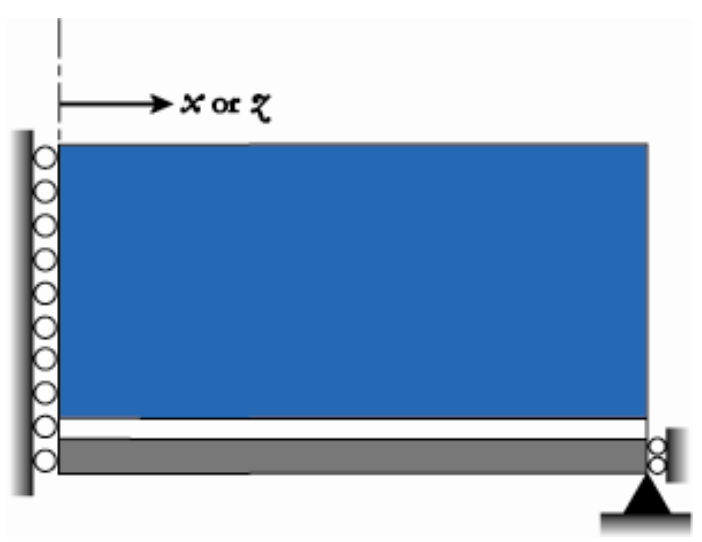

(b) restrained boundary condition, BC2

Figure 17. Structural boundary conditions applied to underlying structure 


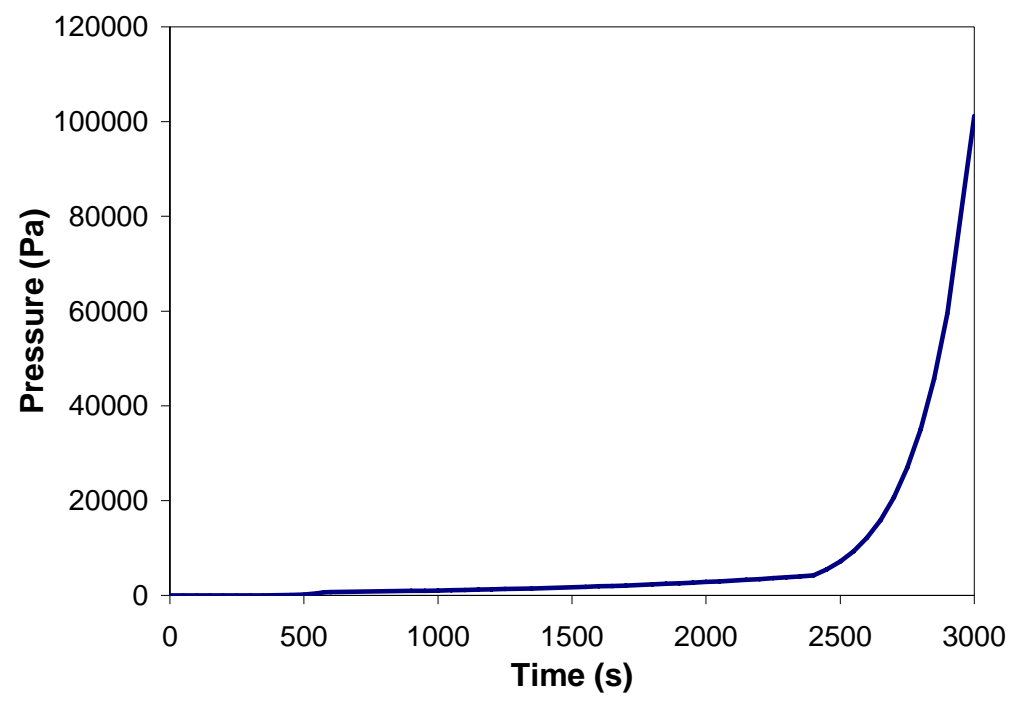

Figure 18. Operating pressure profile used in analysis 